\title{
ARTICLE \\ Mitochondrial oligomers boost glycolysis in cancer stem cells to facilitate blebbishield-mediated transformation after apoptosis
}

\author{
GG Jinesh ${ }^{1}$, JR Molina ${ }^{2}$, L Huang ${ }^{3}$, NM Laing ${ }^{4}$, GB Mills ${ }^{2}$, M Bar-Eli $^{3}$ and AM Kamat ${ }^{1}$
}

Apoptosis culminates in secondary necrosis due to lack of ATP. Cancer stem cells form spheres after apoptosis by evoking the blebbishield emergency program. Hence, determining how blebbishields avoid secondary necrosis is crucial. Here we demonstrate that N-Myc and VEGFR2 control transformation from blebbishields, during which oligomers of K-Ras, p27, BAD, Bax, and Bak boost glycolysis to avoid secondary necrosis. Non-apoptotic cancer cells also utilize oligomers to boost glycolysis, which differentiates the glycolytic function of oligomers from their apoptotic action. Smac mimetic in combination with TNF- $a$ or TRAIL but not in combination with FasL abrogates transformation from blebbishields by inducing secondary necrosis. Thus blebbishield-mediated transformation is dependent on glycolysis, and Smac mimetics represent potential candidates to abrogate the blebbishield emergency program.

Cell Death Discovery (2016) 2, 16003; doi:10.1038/cddiscovery.2016.3; published online 1 February 2016

\section{INTRODUCTION}

Apoptosis culminates in secondary necrosis in most cell types. ${ }^{1}$ Cancer stem cells are capable of avoiding secondary necrosis and forming spheres (undergoing transformation) after apoptosis by evoking the blebbishield emergency program. The blebbishield emergency program exhibits two major phases: a blebbishield phase in which the apoptotic blebs fuse together to reconstruct the cells, and a sphere-formation phase in which blebbishields fuse to each other to form cancer stem cell spheres. ${ }^{2}$ The decision to undergo apoptosis or necrosis is determined by ATP production and thus by glycolysis; ${ }^{3}$ however, it is not yet understood how blebbishields avoid secondary necrosis.

Sphere formation is a hallmark of cellular transformation. Protein translation has a major role in transformation. ${ }^{4}$ Internal ribosome entry site (IRES) translation of proteins during cell death can rewrite the fate of cells: for example, c-Myc, c-IAP2, and XIAP are bona fide antiapoptotic IRES targets. ${ }^{5}$ Smac mimetics represent a novel class of small molecules that downregulate c-IAP2 and induce apoptosis with death ligands. ${ }^{6,7}$

Although apoptosis, glycolysis, IRES translational targets, and transformation are well studied, their role in blebbishieldmediated transformation is not yet understood. Using a Smac mimetic (AZ58) and TNF- $a$, TRAIL, and FasL, here we demonstrate that blebbishields increase glycolysis by forming mitochondrial oligomers of K-Ras, p27, BAD, Bax, and Bak to override secondary necrosis. Oligomers of these proteins in non-apoptotic cancer cells also boost glycolysis, which discriminates the glycolytic functions of oligomers from their apoptotic function. Transformation from blebbishields is mediated by N-Myc and VEGFR2. Caspase-3 targets the expression of VEGFR2 and N-Myc, inhibits glycolysis through Bax cleavage, and induces secondary necrosis in blebbishields to inhibit transformation. Thus glycolysis overrides secondary necrosis to aid blebbishield-mediated transformation and Smac mimetic plus TNF- $a$ or AZ58 plus TRAIL represents a potential combination to target blebbishield-mediated cellular transformation.

\section{RESULTS}

Downregulation of selected IRES translational targets and induction of necrotic PARP cleavage during apoptosis inhibits transformation from blebbishields

We previously reported that bladder cancer cells (RT4 and RT4v6) are capable of blebbishield-mediated sphere formation (transformation) after apoptosis in a p70S6K expression-dependent manner $^{2}$ and that Smac mimetic in combination with TNF- $a$, TRAIL, or FasL induces apoptosis through downregulation of c-IAP2 and XIAP (IRES translational targets). ${ }^{6}$ As IRES translation has pivotal roles in transformation ${ }^{4}$ and p70S6K regulates protein translation, we first examined the expression of p70S6K and a panel of known IRES translational targets that are influenced by apoptosis induced by Smac mimetic AZ58 in combination with TNF- $a$, TRAIL, or FasL in RT4v6 cells. We found that XIAP, c-Myc, $\mathrm{N}-\mathrm{Myc}$, and Tau (referred to as 'selected IRES targets' in this report) and p70S6K were drastically downregulated by the combination of AZ58 with TNF- $a$ or TRAIL but not by the combination of AZ58 with FasL (Figure 1a). Both TNF- $a$ and TRAIL plus AZ58 were efficient in downregulating $\mathrm{c}-\mathrm{Myc}$ and $\mathrm{N}-\mathrm{Myc}$, while FasL plus AZ58 was able to downregulate only c-Myc (Figure 1a). Inhibiting protein translation using cycloheximide $(\mathrm{CHX})$ at a dose of $10 \mu \mathrm{g} / \mathrm{ml}$ also induced robust apoptosis (Supplementary Figure S1a) but without significant downregulation of selected IRES targets except c-Myc (Figure 1b). Despite the differences in degradation of selected IRES targets at $24 \mathrm{~h}$ after treatment, all

\footnotetext{
${ }^{1}$ Department of Urology, The University of Texas MD Anderson Cancer Center, Houston, TX, USA; ${ }^{2}$ Department of Systems Biology, The University of Texas MD Anderson Cancer Center, Houston, TX, USA; ${ }^{3}$ Department of Cancer Biology, The University of Texas MD Anderson Cancer Center, Houston, TX, USA and ${ }^{4}$ Astra Zeneca, Boston, MA, USA. Correspondence: GG Jinesh (goodwinjinesh@gmail.com) or AM Kamat (akamat@mdanderson.org)

Received 17 December 2015; accepted 24 December 2015; Edited by EA Sayan
} 
a

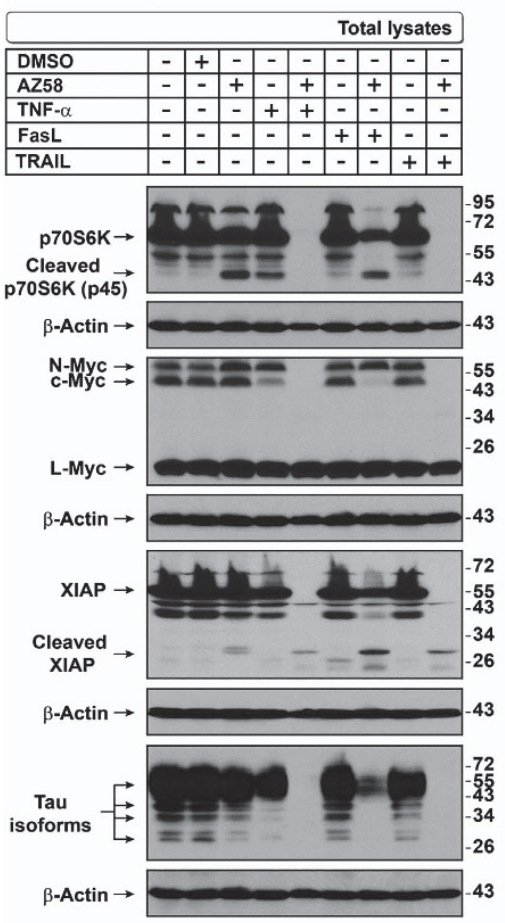

b

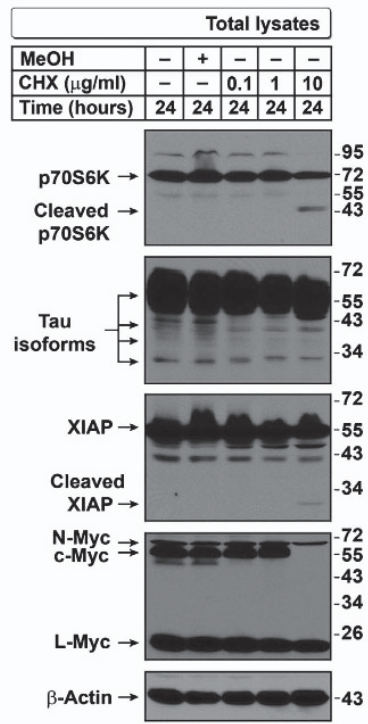

C

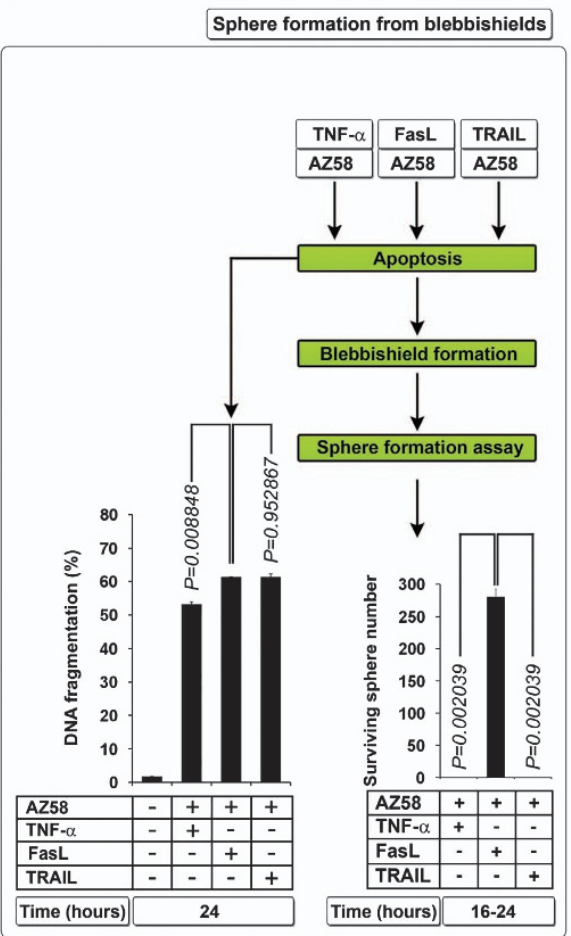

d

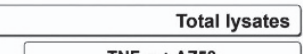

\begin{tabular}{|r|}
\hline Total lysates \\
\hline FasL + AZ58 \\
\hline
\end{tabular}

\begin{tabular}{r|} 
Total lysates \\
\hline TRAIL + AZ58 \\
\hline
\end{tabular}

Tim

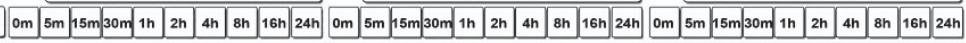
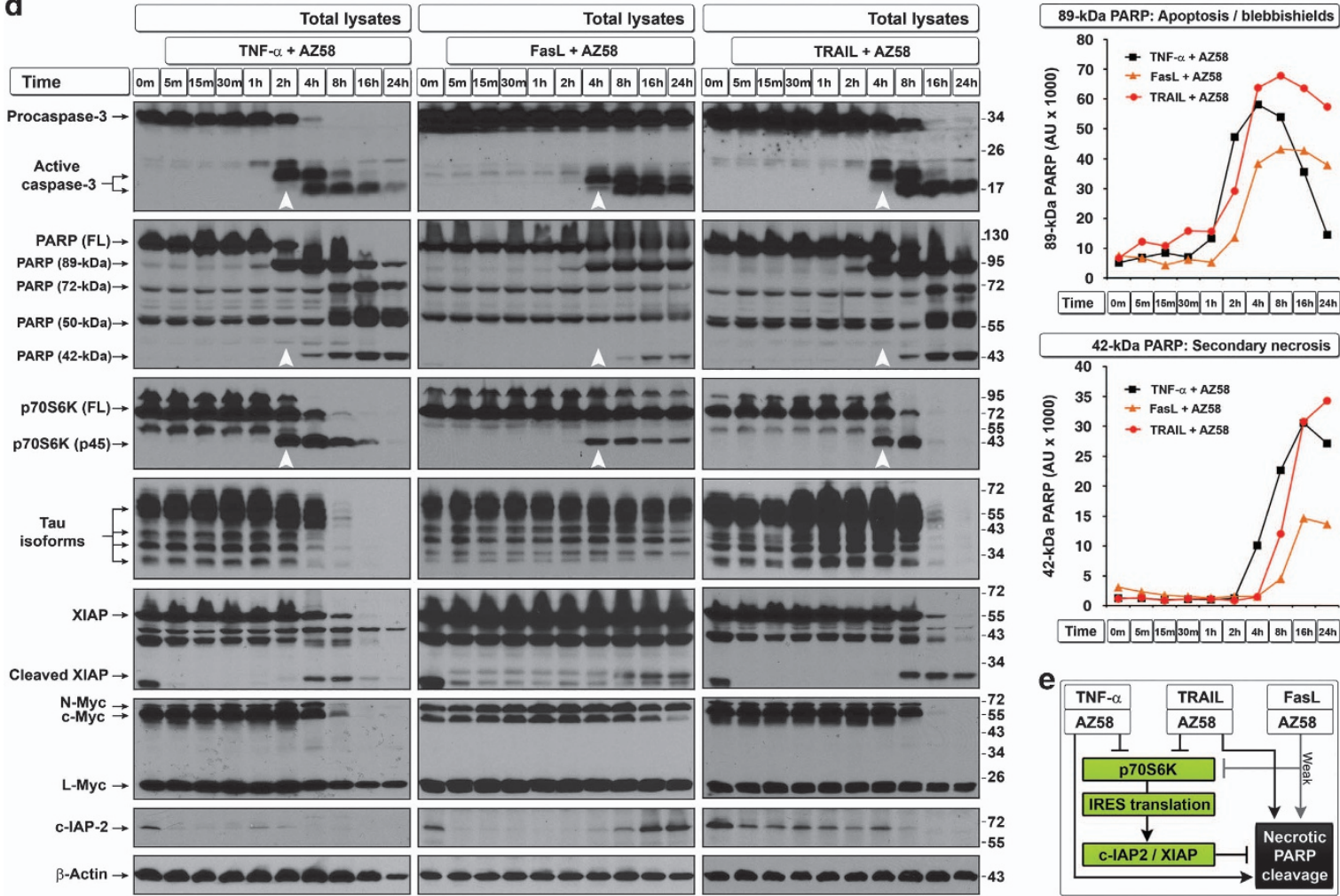

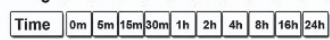
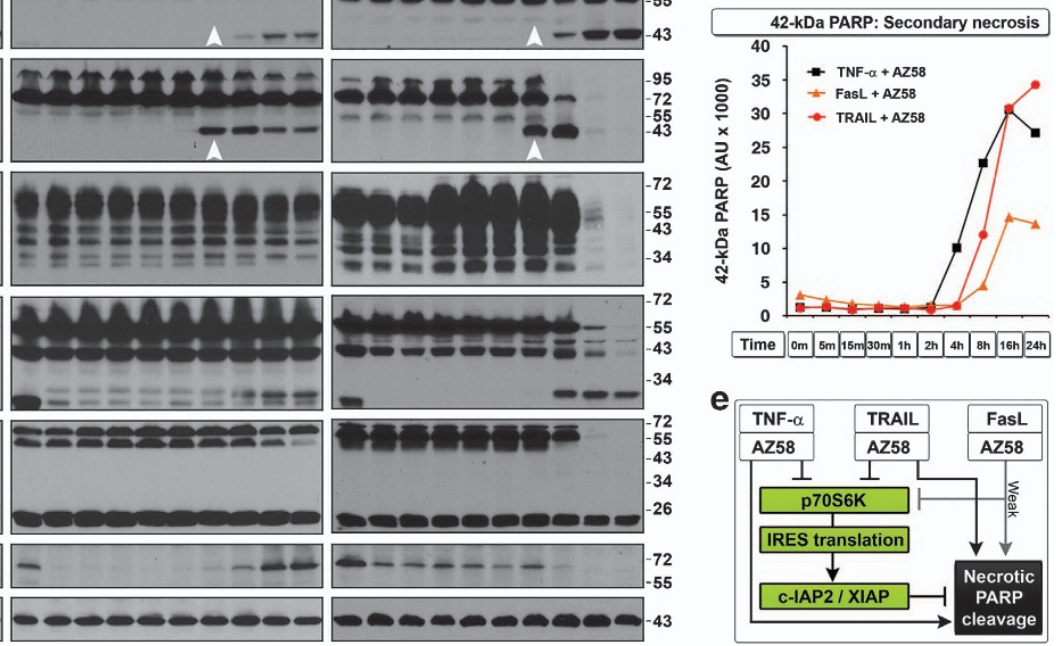

Figure 1. Defective downregulation of IRES targets and defective induction of secondary necrotic PARP cleavage leads to transformation from blebbishields. (a) TNF- $a$ and TRAIL but not FasL in combination with AZ58 downregulate p70S6K and selected IRES translational targets at 24 h. (b) $\mathrm{CHX} 10 \mu \mathrm{g} / \mathrm{ml}$ selectively targets c-Myc expression (also see Supplementary Figure S1A). (c) All three death ligands induce similar levels of DNA fragmentation in RT4v6 cells (left bar graph; $n=3$ ), but only blebbishields induced by FasL+AZ58 could transform (right bar graph; $n=3$ ). (d) Twenty-four hour pulse-chase analysis of timing of degradation of selected IRES translational targets in relation to caspase-3 activation (arrowheads), p70S6K and PARP cleavage (left blot panels), and quantification of apoptotic (89 kDa) and secondary necrotic PARP cleavage $(42 \mathrm{kDa})$ by densitometry (right panels). (e) Schematic representation of lower efficiency of FasL than of TNF- $a$ or TRAIL in combination with AZ58 in downregulating P70S6K and selected IRES targets in relation to secondary necrotic PARP cleavage. 
three death ligands in combination with AZ58 induced pyknosis, blebbishield formation, and DNA fragmentation to a similar extent (Figure 1C and Supplementary Figure S1a). Interestingly, only blebbishields generated from FasL plus AZ58, not blebbishields generated from TNF- $a$ or TRAIL plus AZ58, were capable of sphere formation (Figure 1c).

Because p70S6K controls protein translation by phosphorylation of ribosomal-S6 protein, ${ }^{8}$ we examined the levels of p70S6K (a caspase- 3 substrate) in parallel to caspase- 3 and its substrate PARP to confirm that the IRES targets were downregulated after the loss of p70S6K. Cleavage of p70S6K (resulting in p45 fragment) coincided with caspase-3 activation and 89-kDa PARP cleavage, whereas complete downregulation of full-length p70S6K coincided with downregulation of c-Myc, Tau, and XIAP (Figure 1d). Importantly, downregulation of full-length p70S6K, c-Myc, and Tau coincided with the generation of 50-kDa and 42-kDa necrotic PARP fragments, indicating the onset of secondary necrosis (Figure 1d). ${ }^{9}$ Intriguingly, FasL plus AZ58 did not generate necrotic PARP cleavage as efficiently as TNF- $a$ - or TRAIL plus AZ58 (Figures 1d and e). Although FasL plus AZ58 induced caspase-3 cleavage as early as $4 \mathrm{~h}$ after treatment (similar to TRAIL plus AZ58 at $4 \mathrm{~h}$ ), FasL plus AZ58 was able to downregulate only c-Myc at $24 \mathrm{~h}$, raising the possibility that the cells managed to resume translation. To support this notion, c-IAP2 expression was restored after caspase-3 activation only in cells treated with FasL plus AZ58 but not in cells treated with TNF- $a$ or TRAIL plus AZ58 (Figure 1d). Thus combinations of TNF- $a$, TRAIL, and FasL with AZ58 induce similar levels of apoptosis at $24 \mathrm{~h}$ but with different levels of downregulation of IRES translational targets and secondary necrotic 42-kDa PARP cleavage, resulting in transformation only from FasL plus AZ58-generated blebbishields.

Downregulation of c-Myc is independent of caspase-3-mediated downregulation of other selected IRES translational targets

Caspase-3 inhibition prevented downregulation of p70S6K, Tau, and XIAP and DNA fragmentation in all three combinations of AZ58 with death ligands but prevented downregulation of c-Myc only in the TNF- $a$-containing combination at $8 \mathrm{~h}$ but not at $24 \mathrm{~h}$, indicating that c-Myc degradation could be caspase-3 independent (Figures 2a-c). Morphologically, TNF- $a$ plus AZ58 induced secondary necrosis at $8 \mathrm{~h}$, and this effect was prevented by z-DEVD-fmk (quantified below); despite pyknosis and formation of blebbishields were not prevented (Figure $2 \mathrm{~d}$ and Supplementary Movie S1). These results, together with our finding that $\mathrm{CHX}$ selectively downregulated c-Myc to induce apoptosis, suggested that c-Myc downregulation is independent of caspase-3 activation and is a crucial event to induce apoptosis.

Mitochondrial Bax p18 fragment but not oligomerization of K-Ras, p27, BAD, Bax, and Bak mediates mitochondrial outer membrane permeabilization (MOMP)

Ras signaling is known to stabilize c-Myc at the protein level, ${ }^{10}$ regulate $\mathrm{p} 70 \mathrm{~S} 6 \mathrm{~K}$ expression, ${ }^{11}$ and mediate cellular transformation through Myc. ${ }^{12} \mathrm{~K}$-Ras is well known for its role in cellular transformation; ${ }^{13,14}$ hence, we examined K-Ras signaling. We identified a shift in molecular weight (MW shift) of K-Ras from $21 \mathrm{kDa}$ to approximately 60-70 kDa under apoptotic conditions (Figure 2e). RT4v6 cells had constitutive K-Ras activation (21 kDa) that was abolished by combinations of TNF- $a$, FasL, and TRAIL with AZ58 at $24 \mathrm{~h}$ (both 21-kDa and 70-kDa shifted forms were not active; Figure $2 \mathrm{f}$ ).

The MW shift may be due to oligomerization as many apoptotic regulators are known to undergo oligomerization. ${ }^{15}$ Interestingly, p27 and BAD also exhibited similar MW shifts during apoptosis (Figure 3a). Upon treatment with TNF-a plus AZ58, the K-Ras MW shift occurred as early as $8 \mathrm{~h}$ (Figure $3 \mathrm{~b}$ ).
Under untreated conditions, K-Ras, p27, and BAD were localized in both cytoplasm and nucleus; however, under apoptotic conditions, the MW shift was restricted to the cytoplasm except for p27 (Figure 3c). We further confirmed that the nuclear fractions were not contaminated with Golgi membranes (where Ras can localize) by examining the endoplasmic reticulum-Golgi tethering protein p115 by western blotting and K-Ras nuclear localization by immunofluorescence (Figures $3 c$ and $d$ ). As pro-apoptotic oligomers are known to localize to mitochondria, we examined $\mathrm{K}-\mathrm{Ras}, \mathrm{BAD}$, and p27 localization along with known oligomerizing proteins Bax and Bak ${ }^{16,17}$ in isolated mitochondria from cells treated with TNF- $a$ plus AZ58. At 8 and $24 \mathrm{~h}$ after treatment, $\mathrm{K}$-Ras, p27, and BAD had undergone a MW shift to $70 \mathrm{kDa}$ in mitochondria along with pro-apoptotic Bax and Bak oligomerization, demonstrating that K-Ras, p27, and BAD indeed undergo oligomerization similar to Bax and Bak (Figures 3e and f). We also detected a Bax p18 caspase cleavage fragment and loss of mitochondrial Smac and cytochrome- $C$ in cells treated with TNF- $a$ or TRAIL plus AZ58 but not FasL plus AZ58 (Figure 3f). Bax p18 is known to be more efficient in MOMP than intact Bax. ${ }^{18}$ We further detected K-Ras oligomers in mitochondria-depleted cytosol, demonstrating MOMP (Supplementary Figure S2a). Thus mitochondrial Bax p18 fragment but not oligomerization of K-Ras, p27, BAD, Bax, and Bak during apoptosis leads to MOMP.

$\mathrm{CHX}$ enhances oligomerization of K-Ras, p27, BAD, Bax, and Bak and abolishes transformation from blebbishields by targeting $\mathrm{N}-\mathrm{Myc}$

$\mathrm{CHX}$ at a concentration of $10 \mu \mathrm{g} / \mathrm{ml}$ alone (Supplementary Figure S1a) and CHX $10 \mu \mathrm{g} / \mathrm{ml}$ in combination with TNF-a (as described previously ${ }^{19}$ ) induced equal apoptosis in RT4v6 cells (Figure 4a); however, only the blebbishields from $\mathrm{CHX}$ treatment alone were able to form spheres (Figure $4 b$ ). Microscopic analysis revealed that, compared with $\mathrm{CHX}$ alone, $\mathrm{CHX}$ plus TNF- $a$ accelerated apoptosis at $4 \mathrm{~h}$ (Figure $4 \mathrm{~b}$ ) and induced secondary necrosis at $24 \mathrm{~h}$ (Supplementary Movie S2). In addition, CHX blocked sphere formation from FasL-plus-AZ58-generated blebbishields by $91.4 \%$ (Figure 4c).

We compared the mitochondrial oligomerization status of K-Ras, p27, BAD, Bax, and Bak between sphere-forming blebbishield-inducing conditions (CHX; FasL plus AZ58) and non-sphere-forming blebbishield-inducing conditions (CHX plus TNF- $a$; FasL plus AZ58 plus $(\mathrm{HX}$ ) and found that mitochondrial oligomerization was significantly increased in non-sphereforming blebbishields (Figure 4d). Correspondingly, we detected increased amounts of K-Ras oligomers in mitochondria-depleted cytoplasm, reflecting increased MOMP (Supplementary Figure S2b). As Ras signaling regulates the phosphorylation of BAD at Ser-112 to regulate glycolysis ${ }^{20}$ and glycolysis controls secondary necrosis, ${ }^{3}$ we examined the phosphorylation status of BAD. We found that BAD-Ser-112 phosphorylation was significantly reduced in non-sphere-forming blebbishield mitochondria compared with sphere-forming blebbishield mitochondria (Figure 4d). We also assessed MOMP by Bax p18 detection in mitochondria and loss of Smac and cytochrome- $C$ from mitochondria. We found MOMP in non-sphere-forming blebbishields but not in sphere-forming blebbishields (Figure 4d). These data demonstrated that $\mathrm{CHX}$ in combination with TNF- $a$ or FasL plus AZ58 blocks transformation from blebbishields by augmenting MOMP, which is accompanied by enhanced oligomerization of K-Ras, p27, BAD, Bax, and Bak. In this context, we had reported that mitochondrial depolarization leads to inhibition of transformation from blebbishields. ${ }^{21}$

Furthermore, $\mathrm{CHX}$ enhanced alternative processing of active caspase-9 (Figure 4e) and abolished N-Myc expression in non-sphere-forming blebbishields (Figure 4f). As loss of $\mathrm{N}$-Myc correlated with loss of sphere formation (Figure $2 \mathrm{~b}$ 


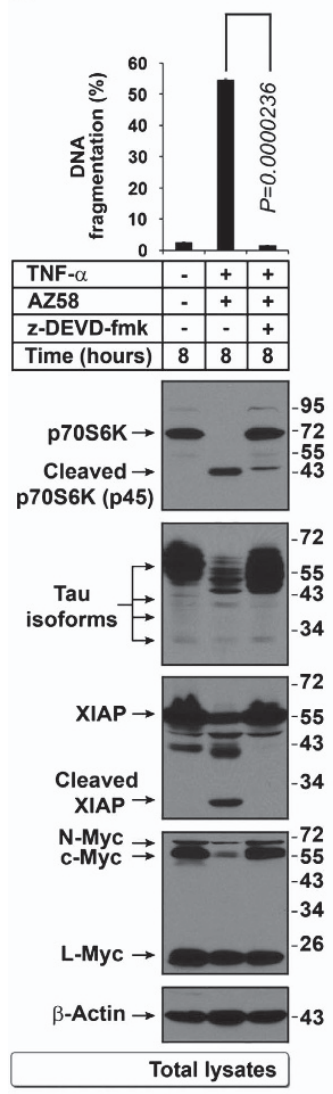

b

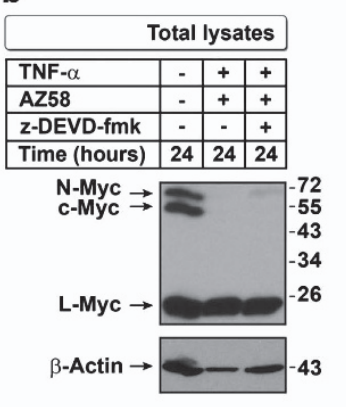

d
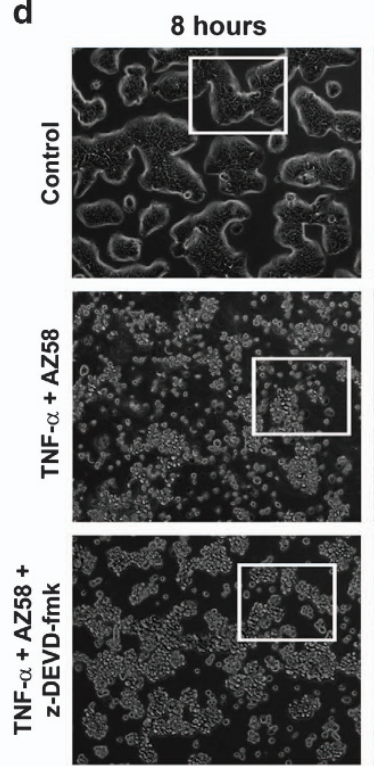

C
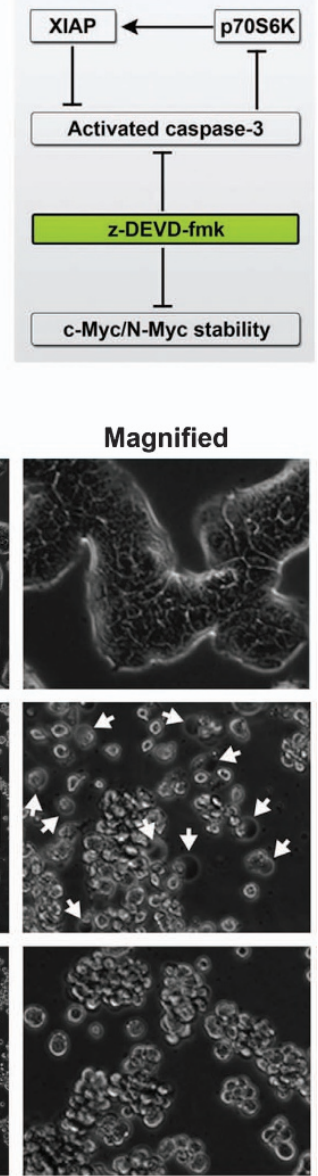

e

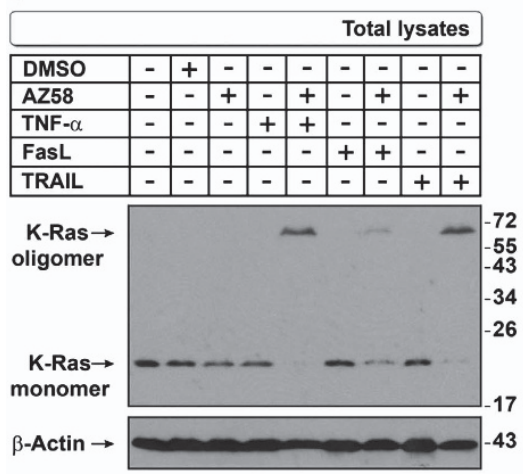

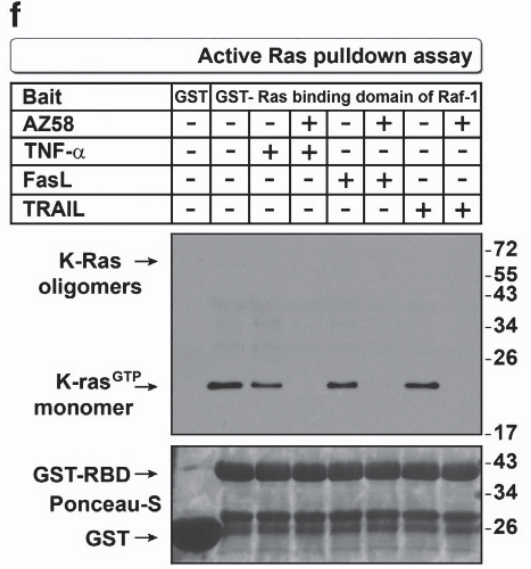

Figure 2. Downregulation of selected IRES targets is regulated by caspase-3 except for c-Myc, which is regulated by K-Ras inhibition. (a-c) Caspase-3 inhibition restores the expression of selected IRES targets but fails to protect c-Myc and N-Myc. Caspase-3 inhibitor z-DEVD-fmk restored Myc isoforms in TNF- $a+$ AZ58-treated cells at (a) $8 \mathrm{~h}$ but failed to restore c-Myc and N-Myc at (b) $24 \mathrm{~h}$. Bar graphs in panel (a) indicate that the DNA fragmentation was prevented by z-DEVD-fmk in all conditions $(n=3)$. The simplified schematic diagram in panel (c) explains the action of z-DEVD-fmk on p70S6K and IRES targets. (d) Caspase-3 inhibition prevents secondary necrosis in blebbishields generated by TNF- $a+A Z 58$ (arrows, secondary necrosis). (e) MW shift (oligomers) of K-Ras with FasL+AZ58 differs in quantity from MW shift with TNF- $a+A Z 58$ or TRAIL+AZ58. (f) K-Ras activation assay. GST-Raf1-RBD binding to K-Ras was abolished by AZ58 combinations with TNF- $a$, FasL, and TRAIL.

and Figures $2 b$ and $4 b, c$, and $f$ ), we examined the requirement of N-Myc for sphere formation by fractionating sphere-forming and non-sphere-forming blebbishields from FasL-plus-AZ58generated blebbishields after allowing $4 \mathrm{~h}$ for sphere formation and found that $\mathrm{N}-\mathrm{Myc}$ was expressed only in sphere-forming blebbishields (Figure 4g). Together, these data demonstrated that $\mathrm{CHX}$ in combination with TNF- $a$ or FasL plus AZ58 abolishes transformation by targeting $\mathrm{N}-\mathrm{Myc}$ for degradation.
Caspase-3 inhibition reveals that oligomerization of K-Ras is not required to block transformation from blebbishields

As loss of N-Myc leads to loss of transformation from blebbishields, we examined whether caspase-3 inhibition could block transformation from blebbishields, because z-DEVD-fmk abolishes N-Myc expression (Figures 2a and b). Caspase-3 inhibition abolished transformation from FasL-plus-AZ58-induced blebbishields (Figure $4 \mathrm{~h}$ ) and failed to rescue transformation from 
a

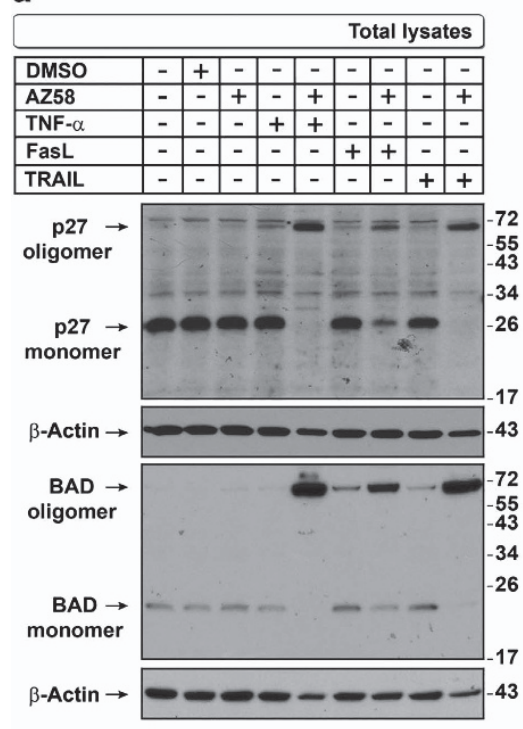

b

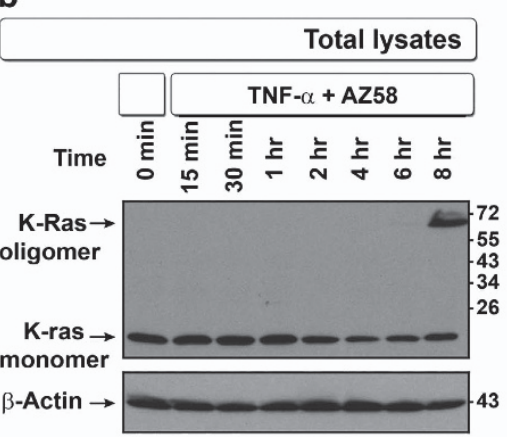

d

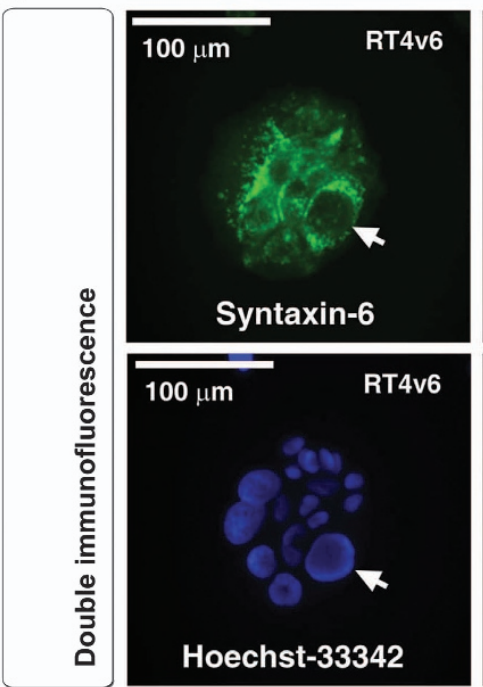

C

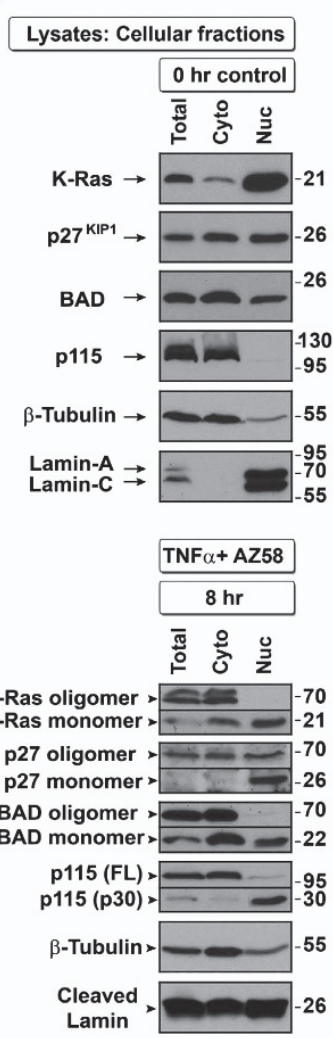

e
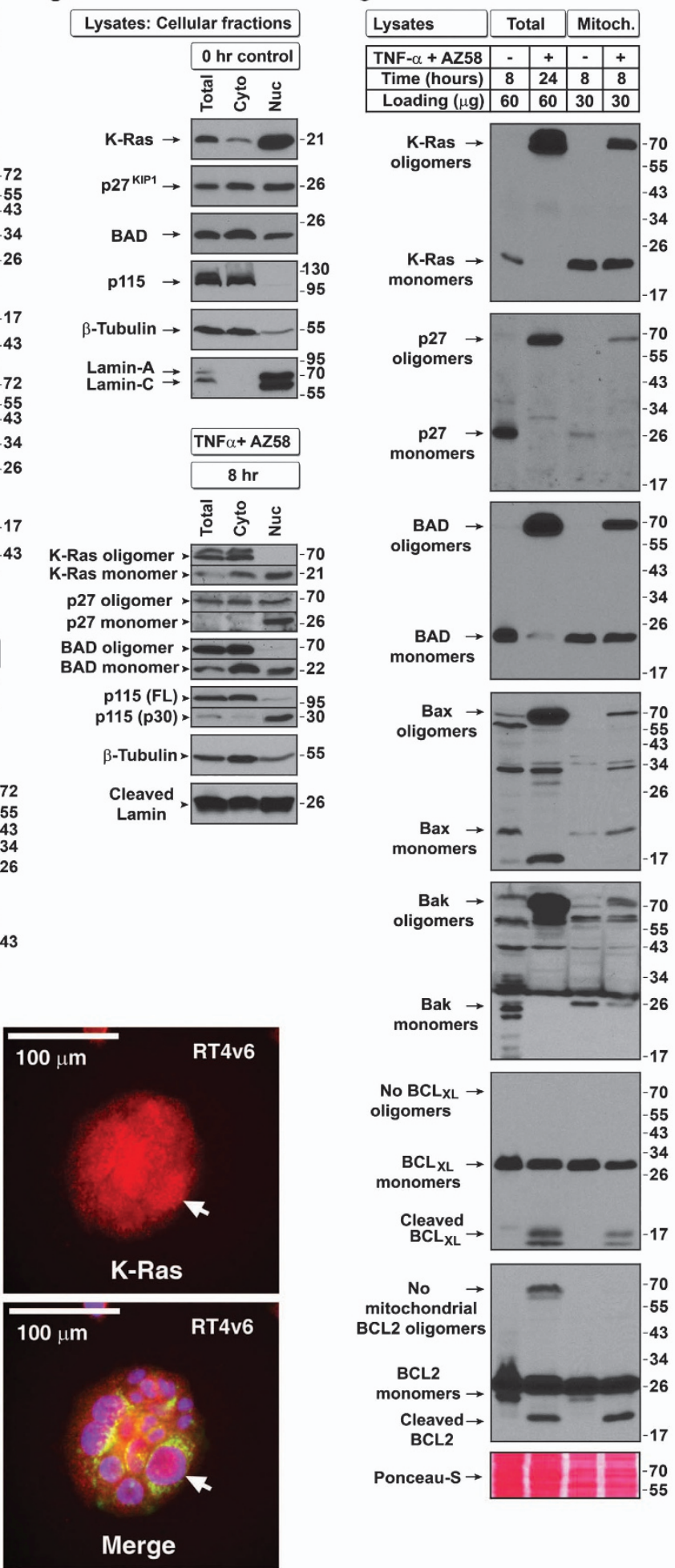

f

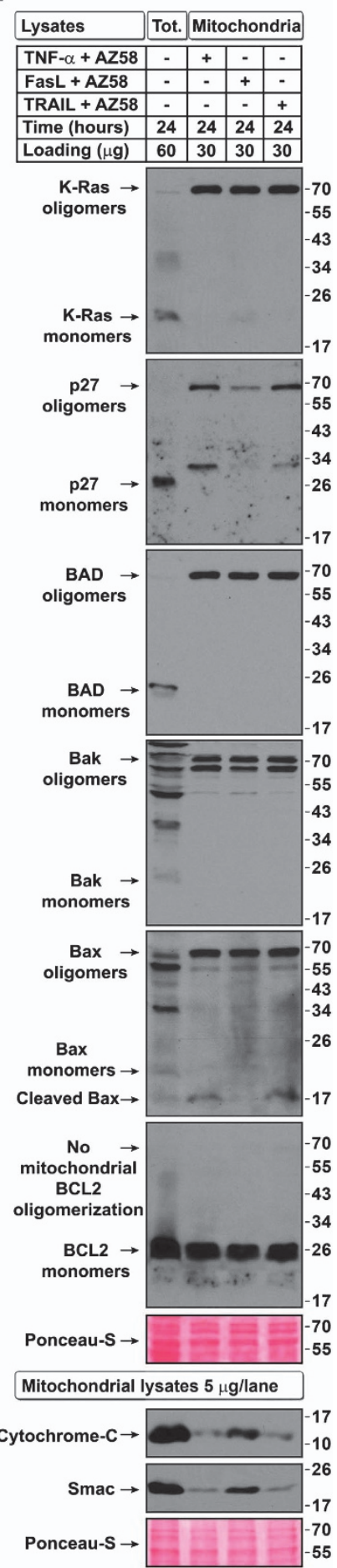

Figure 3. Cleaved Bax but not oligomers of K-Ras, p27, BAD, Bax, and Bak in apoptotic mitochondria correlates with inhibition of transformation from blebbishields. (a) TNF- $a$ and TRAIL induce MW shift in p27 and BAD more efficiently than FasL+AZ58 does at $24 \mathrm{~h}$ time point examined by western blotting. (b) TNF- $a+A Z 58$ induces MW shift in K-Ras as early as $8 \mathrm{~h}$ after treatment. (c) Nuclear and cytoplasmic fractionation of control cells (top panel) and TNF-a+AZ58-treated apoptotic cells at $8 \mathrm{~h}$ (bottom panel) to explore localization of K-Ras, p27, and BAD. No full-length lamin A/C was detected in treated apoptotic cells. (Note that cleaved 30-kDa fragment of p115 can enter the nucleus during apoptosis. ${ }^{34}$ ). (d) Double immunofluorescence confirmation of nuclear localization of K-Ras (arrows). Syntaxin-6 marks perinuclear Golgi membranes. (e) Localization of oligomers in mitochondrial fractions as early as $8 \mathrm{~h}$ after TNF- $a+A Z 58$ treatment. Note that neither BCL nor BCL2 from antiapoptotic members formed oligomers in mitochondria, although BCL2 oligomerized at non-mitochondrial sites. (f) Comparative mitochondrial oligomerization of K-Ras, p27, BAD, Bax, and Bak at $24 \mathrm{~h}$ and associated Smac and cytochrome-C release from mitochondria. Fas $L+A Z 58$ had reduced release of Smac and Cytochrome-C. First lane is total lysates except Smac and Cytochrome- $C$, which are control mitochondrial lysates. 
a

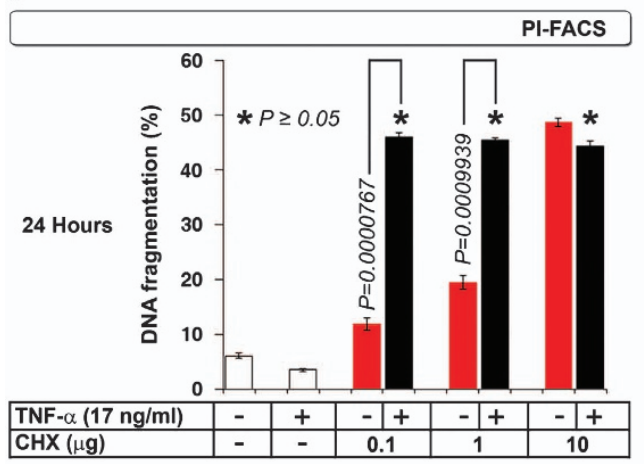

b

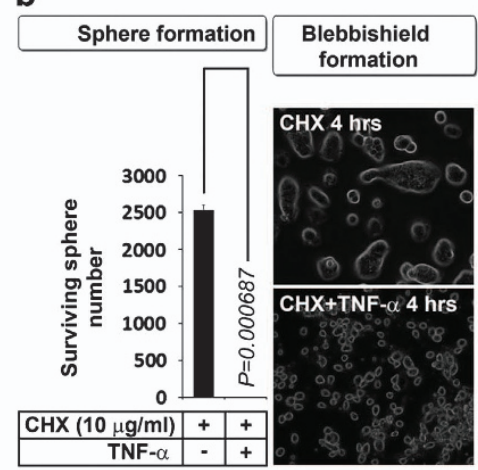

e

Sphere formation from blebbishields

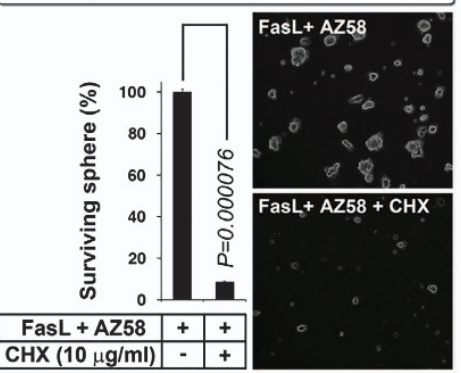

f

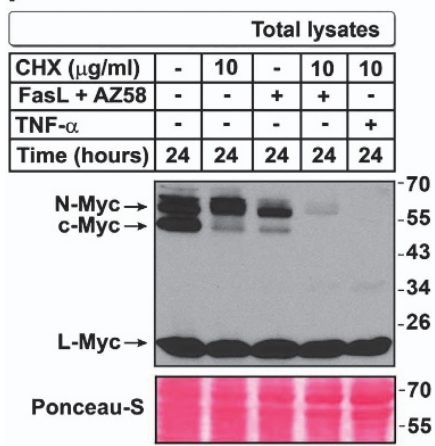

g

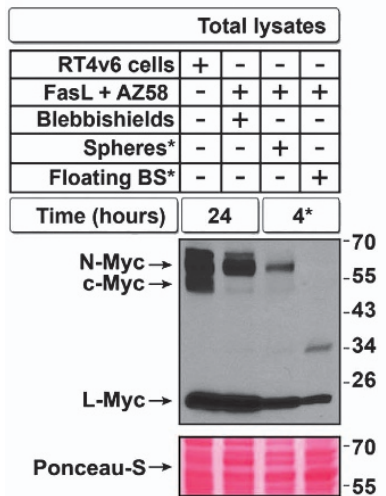

h
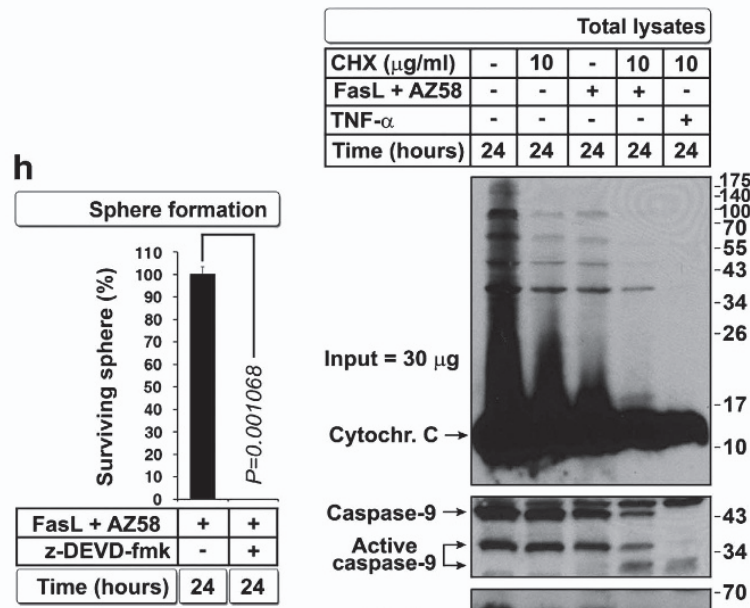

Cytochr. C -

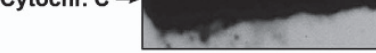

Caspase-9 $\rightarrow-43$

Active
caspase-9 $\longrightarrow-3$

$\beta$-Actin

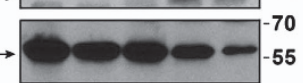

i

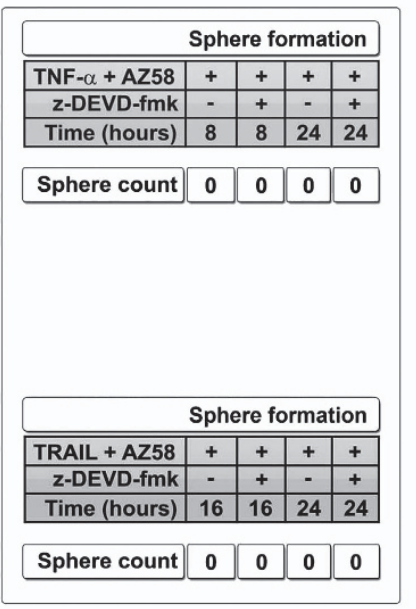

j
Input $=\mathbf{3 0} \mu \mathrm{g}$ d
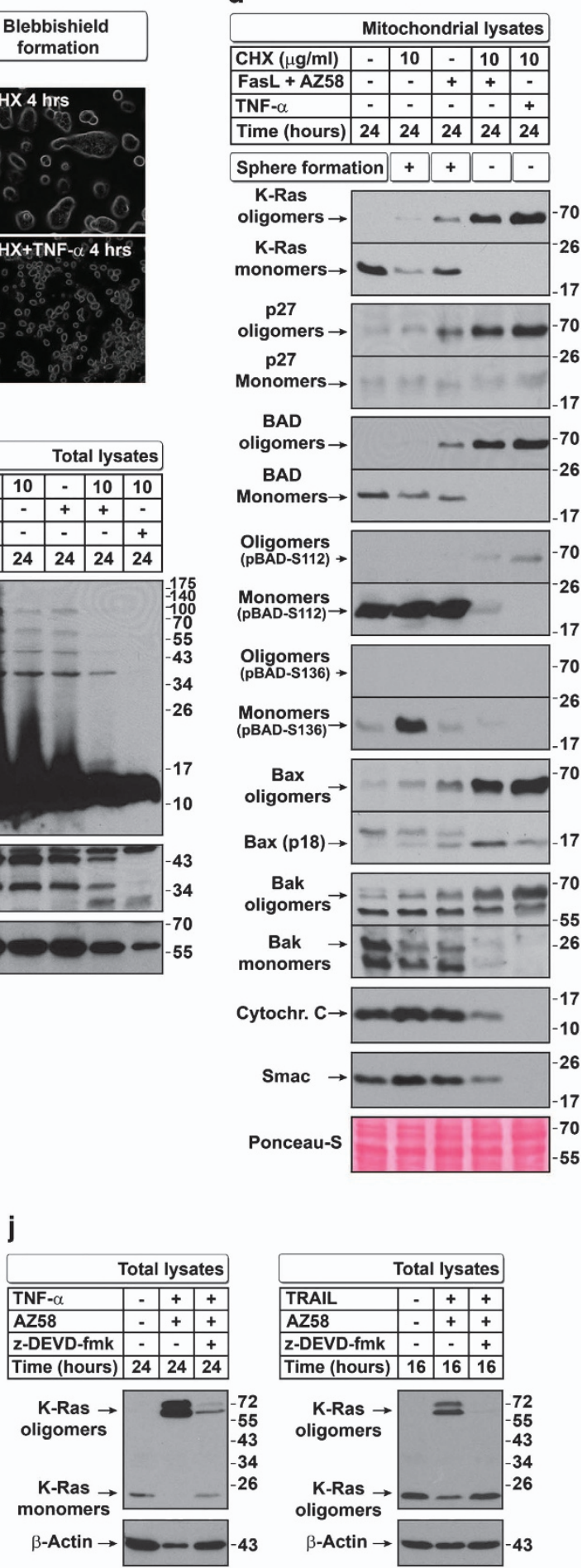

Figure 4. CHX and z-DEVD-fmk regulate oligomerization of K-Ras, p27, BAD, Bax, and Bak, and N-Myc expression but not oligomerization is required for

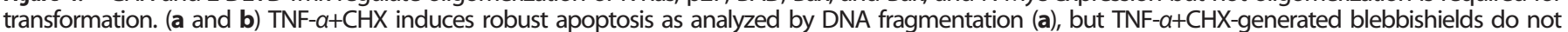
form spheres (b). $P \geq 0.05$ in panel (a) indicates no significant differences in DNA fragmentation between three CHX dose combinations ( $n=3$ ) (comparison of black bars only). Inset in panel (b) shows early induction of blebbishields by TNF- $a+C H X$. No treatments were carried out during transformation phase. (c) CHX inhibits transformation of FasL+AZ58-generated blebbishields. No treatments were carried out during sphere formation phase. (d-f) CHX not only enhances mitochondrial oligomerization of K-Ras, p27, BAD, Bax, Bak, and pBAD ${ }^{112}$ but also enhances Bax cleavage and release of Smac and cytochrome-C (d), resulting in differential caspase-9 cleavage (e) and loss of N-Myc and c-Myc (f). (g) N-myc is expressed in sphere-forming but not in non-sphere-forming (floating) blebbishields. *BS, blebbishields isolated after 24-h treatment; Spheres*, allowed transformation time $4 \mathrm{~h}$. (h and i) Caspase inhibition abolishes transformation from FasL+AZ58-generated blebbishields (h) and fails to rescue sphere formation from TNF-a+AZ58- or TRAIL +AZ58-generated blebbishields (i). No treatments were carried out during sphere-formation phase. (j) Caspase inhibition blocks oligomerization of K-Ras. 
blebbishields induced by TNF- $a$ plus AZ58 or TRAIL plus AZ58 (Figure 4i), which further confirmed the role of $\mathrm{N}$-Myc in transformation from blebbishields. Next, we examined whether oligomerization of K-Ras has any role in inhibiting sphere formation from blebbishields. For this purpose, we chose combinations of TNF- $a$ or TRAIL and AZ58 with or without z-DEVD-fmk (none of these conditions formed spheres). Caspase-3 inhibition blocked oligomerization of K-Ras (Figure 4j) but failed to rescue transformation (Figure $4 \mathrm{i}$ ), demonstrating that oligomerization of K-Ras is not required to inhibit transformation from blebbishields.

Oligomerization reflects energy demand and glycolytic status in blebbishields, but transformation is regulated by VEGFR2 and N-Myc Because K-Ras oligomerization is not required to inhibit transformation from blebbishields (Figures $4 \mathrm{i}$ and $\mathrm{j}$ ) and because we previously reported higher sphere formation of VEGFR2 $2^{\text {High }}$ cells than VEGFR2 ${ }^{\text {Low }}$ cells, ${ }^{2}$ we investigated the VEGF signaling pathway. VEGF-A and VEGFR2 are required for transformation from blebbishields. ${ }^{22}$ TNF- $a$, FasL, and TRAIL plus AZ58 induced secretion of significant amounts of VEGF-A isoforms (Figure $5 \mathrm{a}$ ); however, TNF- $a$ plus AZ58 and TRAIL plus AZ58 but not FasL plus AZ58 abolished the expression of VEGFR2 at $24 \mathrm{~h}$ (Figure $5 \mathrm{~b}$ ). Recombinant VEGF-A (under serum-free conditions) induced increases in $\mathrm{pBAD}^{112}$, activated p70S6K, and N-Myc expression Figure $5 \mathrm{c}$ ) and activated K-Ras in the presence or absence of serum (Figures $5 \mathrm{~d}$ and e). Furthermore, $z$-DEVD-fmk rescued $\mathrm{pBAD}^{112}$ and VEGFR2 expression (Figure $5 f$ ), suggesting that VEGF signaling has a dominant role in blebbishield-mediated transformation.

Interestingly, K-Ras, p27, and BAD are all linked to glucose metabolism. ${ }^{23-25}$ Furthermore, p27 has a facultative role as a glucose sensor. ${ }^{25}$ Hence, we measured the lactate released from cells as a measure of glycolytic state. Formation of blebbishields was associated with higher lactate production compared with lactate production in non-apoptotic live cells (at $6 \mathrm{~h}$ ); however, only blebbishields from the FasL plus AZ58 combination exhibited a steady increase in lactate production over time, indicating that only blebbishields from this condition continued to perform glycolysis (Figure $5 \mathrm{~g}$ ). Furthermore, glucose uptake was maximal in live control cells, whereas only blebbishields from the FasL plus AZ58 combination exhibited steady glucose uptake over time (Supplementary Figure S3a). Similarly, only blebbishields induced by FasL plus AZ58 exhibited a steady increase in lactate production during transformation (Figure $5 \mathrm{~h}$ ). Secondary necrosis in blebbishields leads to glucose spillage and increased the levels of glucose in medium above the levels present originally (Figure 5i). However, lactate measurements reflected the glycolytic state irrespective of secondary necrosis (Supplementary Figure $\mathrm{S} 3 \mathrm{~b})$. Interestingly, caspase-3 inhibition rescued lactate production in blebbishields induced by combinations of TNF- $a$ plus AZ58, TRAIL plus AZ58, and TNF- $a$ plus CHX (Figure 5j).

As glycolysis controls ATP production and ATP determines secondary necrosis, we examined the level of secondary necrosis in isolated post-pyknotic cells and found that low lactate production in blebbishields correlated with higher secondary necrosis and release of cytochrome- $C$ into medium, whereas $z$-DEVD-fmk reversed both secondary necrosis and cytochrome- $C$ release into media (Figure $5 \mathrm{k}$ compared with Figure $5 \mathrm{j}$ and Supplementary Figure S3c). The blebbishields that lacked secondary necrosis were indeed viable (Supplementary Figure S4). These data suggested that oligomerization of K-Ras, p27, and BAD reflects the glycolytic energy demand to meet the apoptotic events and that caspase- 3 inhibition minimizes the apoptotic energy demand and thereby minimizes the need to form oligomers of K-Ras, p27, and BAD. We blocked ATP production in RT4v6 cells by previously reported agents such as NaF and $\mathrm{N}$-ethylmaleimide (NEM) ${ }^{26}$ to examine whether oligomerization is related to ATP availability. We found that both agents induced robust oligomerization of $\mathrm{K}$-Ras, p27, BAD, Bax, and Bak with associated blockade in lactate production, demonstrating that ATP paucity owing to glycolytic shut-down is the cause of oligomerization (Figures $6 a$ and $c$ ). To further examine whether interfering with glycolysis using a specific inhibitor of glycolysis could form oligomers, we used 2-deoxyglucose (2-DG; introduced in MEM), $1: 1$ with normal glucose (MEM component). We found that 2-DG could generate oligomerization of K-Ras, p27, and BAD in non-apoptotic cells (Figure 6b). However, under FasL-plus-AZ58induced apoptotic conditions, 2-DG reduced oligomerization as well as lactate production (Figures $6 \mathrm{~b}$ and $\mathrm{d}$ ), demonstrating the existence of a feed-forward loop during apoptotic oligomerization.

Furthermore, sphere-forming blebbishields expressed oligomers of K-Ras, p27, BAD, Bax, and Bak, demonstrating that these oligomers are not detrimental to sphere-forming blebbishields (Figure 6e). However, the non-sphere-forming blebbishields expressed cleaved Bax p18 and Bak p18 fragments, suggesting the importance of MOMP in blebbishield death (Figure 6e).

$\mathrm{K}$-Ras is known to augment glycolysis in transformed cells, ${ }^{24}$ and some cell types are highly glycolytic under non-apoptotic conditions. $^{27}$ We found that $253-\mathrm{J}$ cells (parental cells: $253 \mathrm{~J}-\mathrm{P}$ ) exhibited constitutive oligomerization of K-Ras and had 10-fold higher glycolytic rate and glucose uptake than RT4v6 cells at equal cell density (RT4v6 cells do not have constitutive K-Ras oligomerization) (Figures $6 \mathrm{f}$ and $\mathrm{g}$ ). We also screened 43 cancer cell lines (excluding tumor samples) from various cancer types and found that 32 of these cell lines (74\%) exhibited constitutive K-Ras, p27, BAD, and Bax oligomerization (Figure 6h). Together, these data demonstrated that oligomerization boosts glycolysis in apoptotic and non-apoptotic cells.

\section{DISCUSSION}

Our study evaluated the intricate network of apoptosis, glycolysis, IRES translational targets, and cellular transformation in the context of blebbishields as summarized in Figure 7. We found that FasL differs from TNF- $a$ and TRAIL in that FasL supports transformation from blebbishields. In support of this notion, acquisition of FasL and Fas expression in cancers might be an important cause of recurrence after therapy, possibly through blebbishield emergency program. ${ }^{28}$

In the current study, we identified the important roles of oligomers in boosting glycolysis to override secondary necrosis in blebbishields and in non-apoptotic cancer cells. K-Ras signaling is known to induce $\mathrm{pBAD}^{112}$ and glycolysis ${ }^{20}$ and mediate cellular transformation by metabolic switch in collaboration with p27, BAD, N-Myc, VEGFR2, and Raf-1 (Supplementary Table S1); all of these molecules have a central role in blebbishield-mediated transformation. Hence, we conclude that blebbishield emergency program is an essential intermediate step in K-Ras-mediated cellular transformation.

Oligomerization of K-Ras, p27, BAD, Bax, and Bak in nonapoptotic cells demonstrates that the oligomers observed in this study are for glycolytic function than for mediating MOMP. MOMP induced by Bax p18 fragment is another crucial aspect in blocking the blebbishield emergency program.

Overall, our study uncovered the importance of glycolysis and its regulation by mitochondrial oligomers of K-Ras, p27, BAD, Bax, and Bak in preventing secondary necrosis to facilitate $\mathrm{N}$-Myc- and VEGFR2-mediated transformation from blebbishields and identified AZ58 plus TNF- $a$ and AZ58 plus TRAIL as potential therapeutic combinations to target blebbishield-mediated cellular transformation. 
a

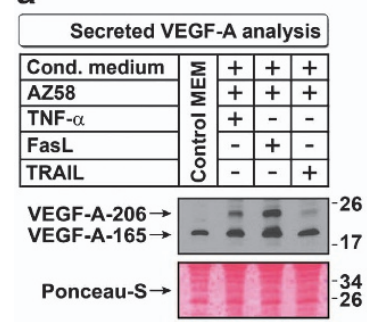

b

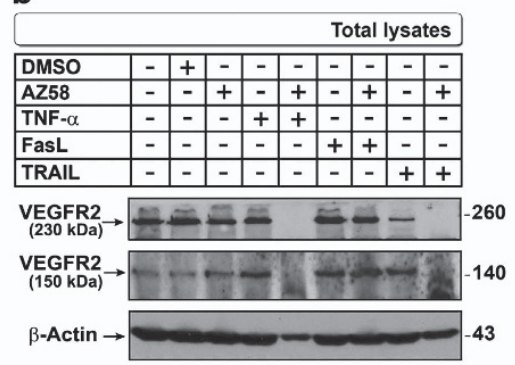

e

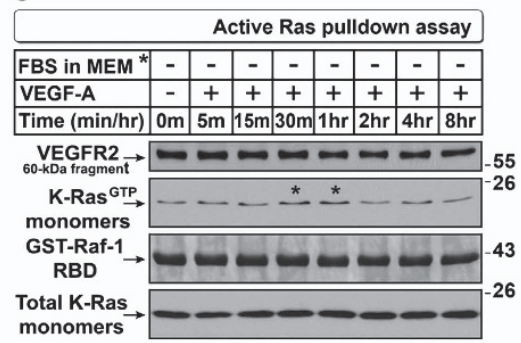

c

$\mathbf{f}$
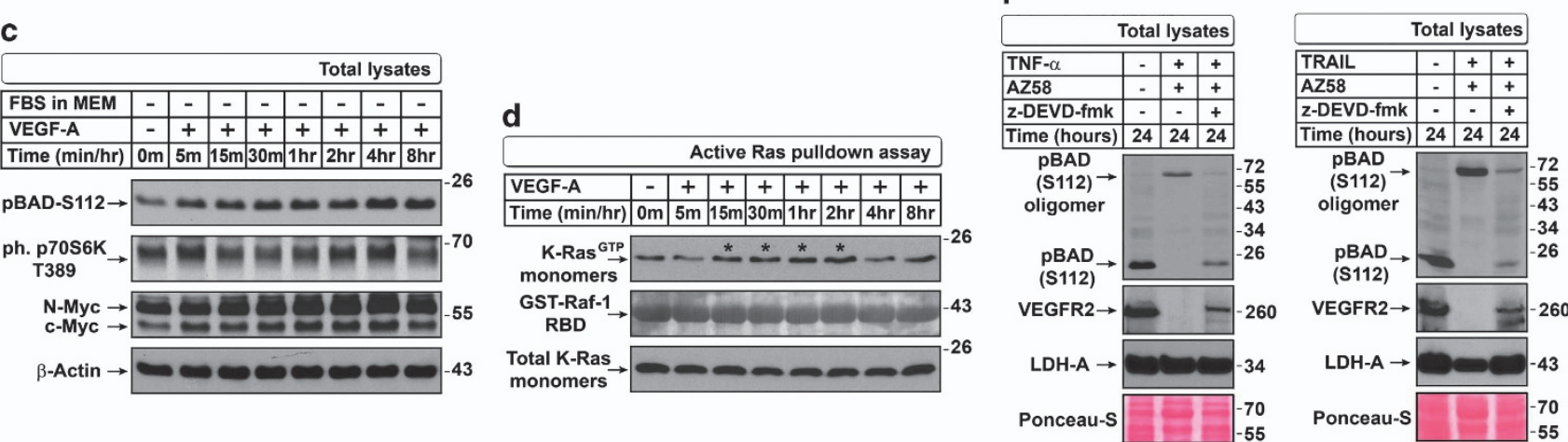

g

h
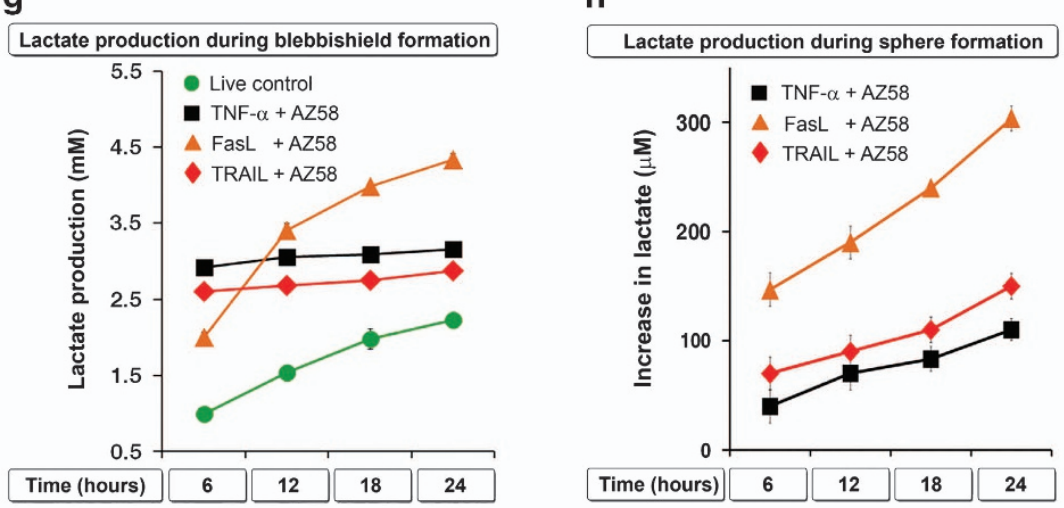

i

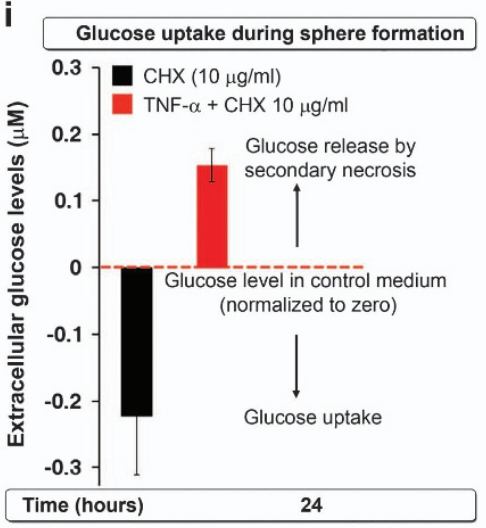

j

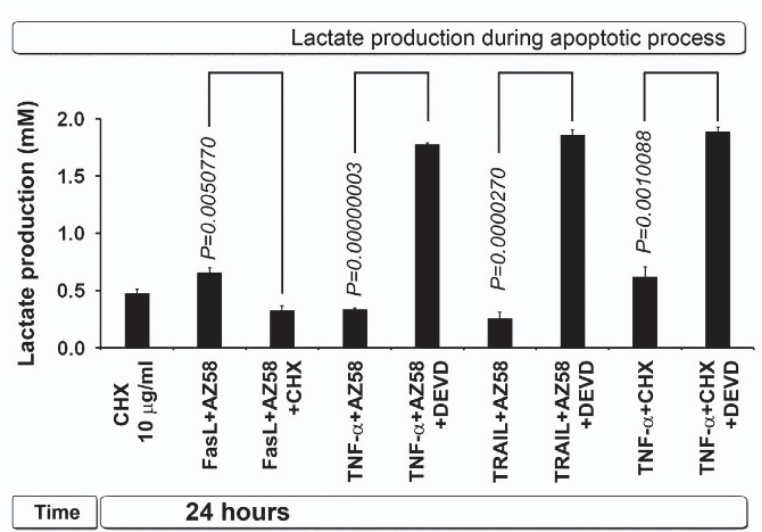

k

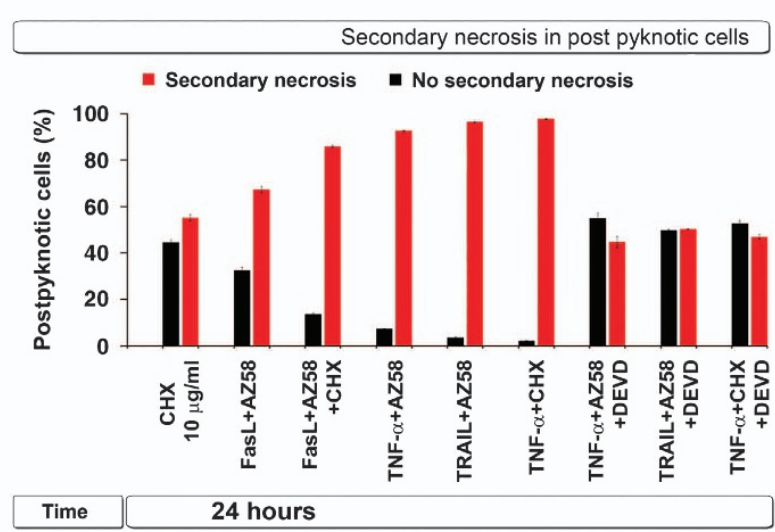

Figure 5. VEGF signaling regulates N-Myc stability and glycolysis to override secondary necrosis in blebbishields. (a) Death ligands in combination with AZ58 enhance secretion of VEGF-A isoforms detected by western blotting of conditioned media. (b) TNF- $a$ or TRAIL but not FasL in combination with AZ58 targets VEGFR2 for degradation. (c) Recombinant VEGF-A induces pBAD ${ }^{\text {S112 }}$ and phospho p70S6K and upregulates N-Myc and c-Myc in serum-free conditions (serum withdrawn $2 \mathrm{~h}$ before and during VEGF treatment). (d and e) K-Ras is constitutively activated in RT4v6 cells and upregulated $(*)$ by VEGF in the presence of serum (d) or in serum-free conditions (e). A VEGFR2 fragment interacts with Raf-1 (e). Note: RT4v6 cells have autocrine VEGF signaling. (f) z-DEVD-fmk rescues loss of pBAD $\$ 112$ and VEGFR2 induced by TNF- $a$ or TRAIL in combination with AZ58. LDH-A: loading control. ( $\mathbf{g}$ and $\mathbf{h}$ ) FasL+AZ58 exhibits uninterrupted glycolysis during blebbishield formation (g) and sphere formation (h) as measured by lactate in conditioned media. (i) Glucose uptake measurement is not suitable for sphere-formation phase, as it is complicated by spillage of intracellular glucose by secondary necrosis. ( $\mathbf{j}$ and $\mathbf{k}$ ) CHX reduces lactate production and enhances secondary necrosis in combination with FasL+AZ58 or TNF- $a$; z-DEVD-fmk rescues lactate production and prevents secondary necrosis. Corresponding viability analysis is shown in Supplementary Figure S5. 
a

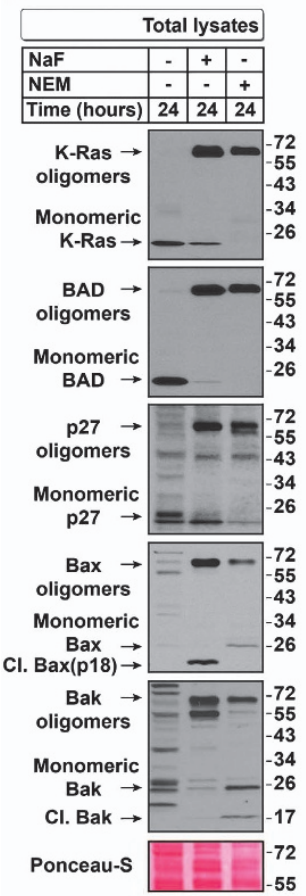

b

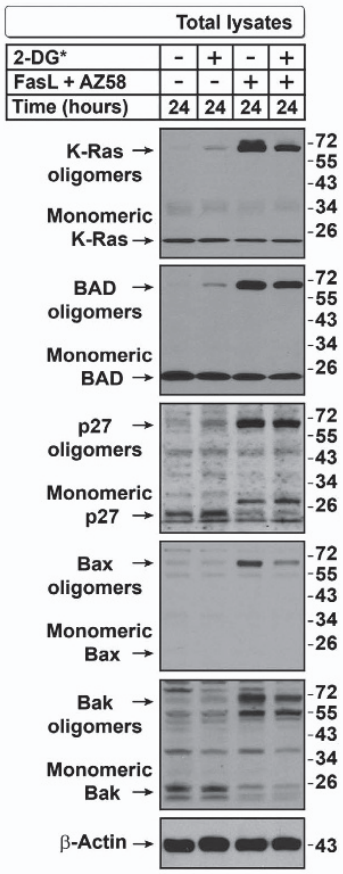

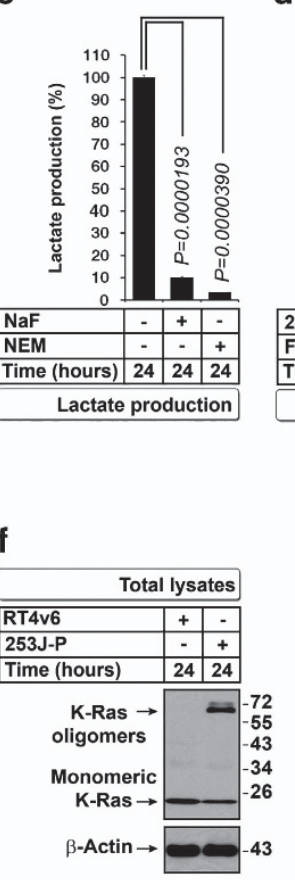

d
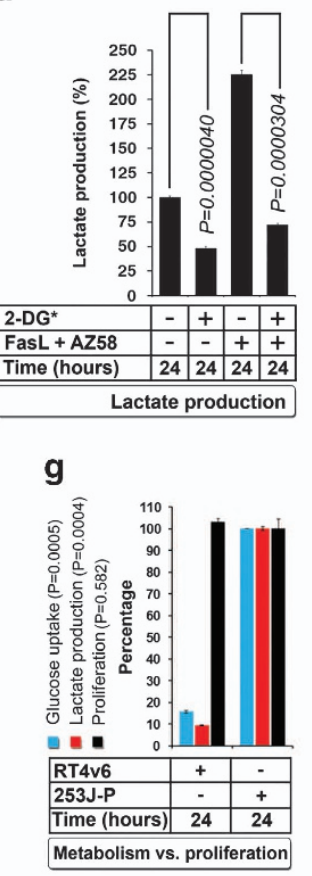

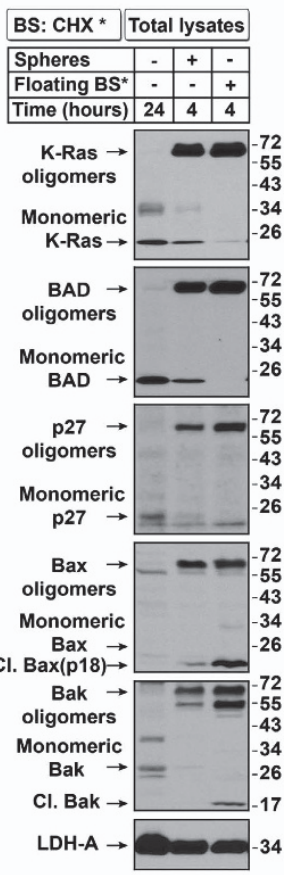

h
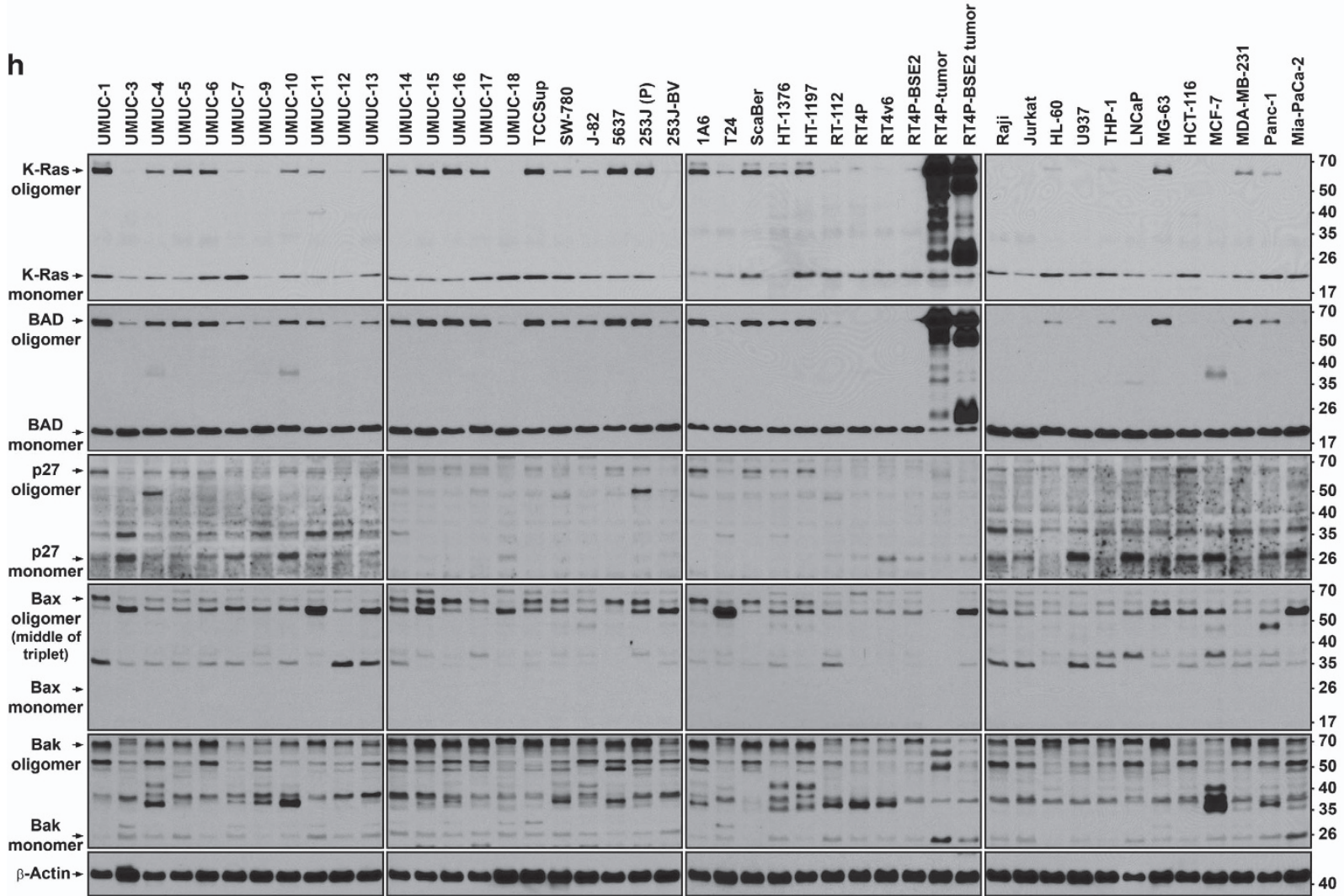

Figure 6. Oligomers of K-Ras, p27, BAD, Bax, and Bak boost glycolysis in blebbishields and non-apoptotic cells. (a) NaF and NEM enhance oligomerization of K-Ras, BAD, p27, Bax, and Bak. (b) 2-Deoxyglucose (2-DG*) induces oligomerization in non-apoptotic cells but interferes with oligomerization in FasL +AZ58-generated blebbishields. (c and d) NaF, NEM, and 2-DG* inhibit lactate production, reflecting inhibition of glycolysis. Controls considered 100\%. Note that FasL+AZ58 increases glycolysis (apoptotic energy demand) (c) as well as oligomerization $(\mathbf{b})(n=3)$. (e) Oligomers are expressed in both sphereforming and non-sphere-forming blebbishields (floating BS*, floating blebbishields); monomers are expressed only in sphere-forming blebbishields. *BS: CHX, blebbishields generated by treatment with $\mathrm{CHX} 10 \mu \mathrm{g} / \mathrm{ml}$ for $24 \mathrm{~h}$. (f and g) Oligomers represent highly glycolytic cancer cells under non-apoptotic conditions. $253 \mathrm{~J}$ JP cells constitutively express K-Ras oligomers (f) and have increased glucose uptake and lactate production although proliferation differences were insignificant (g). $253 \mathrm{~J}$-P measurements were considered $100 \%(n=3)$. (h) Oligomers are widely expressed in cancer cells under non-apoptotic conditions and in vivo (tumor samples: BSE2, tumors from blebbishield-derived cells). Bax reference band (arrow) is the middle of a triplet of oligomers of UMUC-15 that also correlates with K-Ras and BAD patterns across cell lines (also refer to Bax oligomers in panel (a)). 


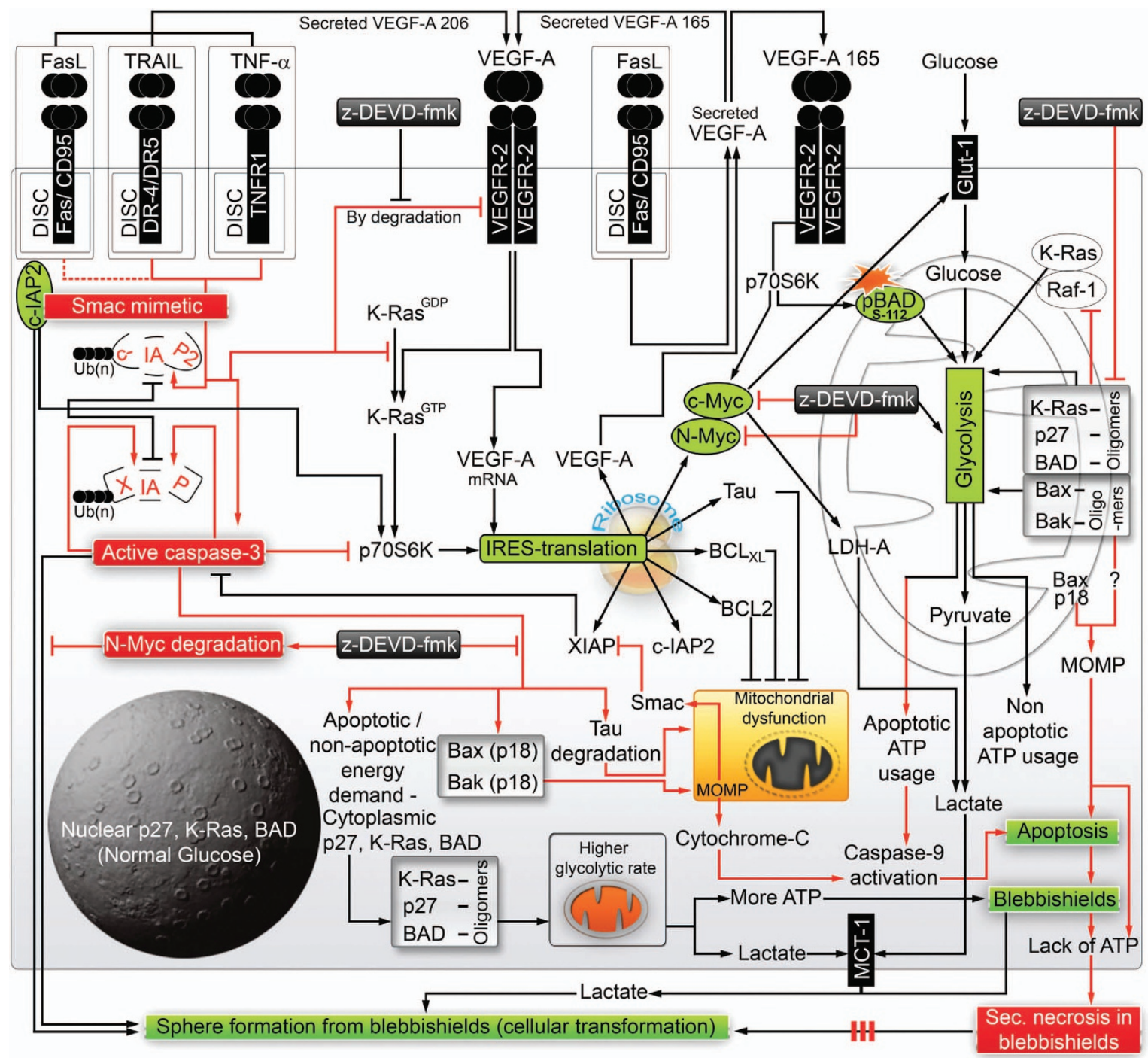

Figure 7. Schematic diagram showing intricate network of cytokines and glycolysis regulating life (transformation) and death decisions of blebbishields. FasL+AZ58 is a weak signal leading to weaker degradation of c-IAP2 (red dotted line). The solid red lines show the events that lead to demise of blebbishields by MOMP, caspase-3 and caspase-9 activation, glycolytic shut-down, ATP depletion, and secondary necrosis. Black arrows indicate survival signals. Although z-DEVD-fmk rescues glycolysis, VEGFR2 expression, and many IRES targets, it does not rescue transformation from blebbishields as it targets c-Myc and N-Myc expression. Red boxes, key destructive signals. Green boxes, key survival signals.

\section{MATERIALS AND METHODS}

Cells and maintenance

Human RT4v6 bladder cancer cells and non-bladder cancer cell lines were described previously. ${ }^{2}$ Various bladder cancer cell lines were kindly provided by Dr. David J McConkey (Department of Urology, The University of Texas MD Anderson Cancer Center, Houston, TX, USA). All cells were maintained in MEM/RPMI with $10 \%$ fetal bovine serum, L-glutamine, pyruvate, non-essential amino acids, vitamins, penicillin, and streptomycin.

\section{Antibodies}

Antibodies to p27 (2552), phospho S-235/236 S6 ribosomal protein (2211), XIAP (2045), c-Myc (5605), p70S6K (2708), Syntaxin-6 (2869), $\beta$-Tubulin (2146), pBAD-S112 (9296), pBAD-S136 (9295), ph-p70S6K T389 (9206), and LDH-A (3582) were purchased from Cell Signaling Technology (Beverly, MA, USA). Antibodies to Cytochrome-C (S2050) and c-IAP-2 (51-9000062) were purchased from BD Biosciences (San Jose, CA, USA). Antibodies to Tau (Sc-21796), BCL2

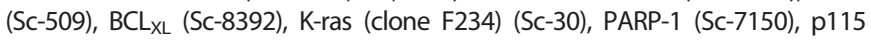
(Sc-48363), Lamin A/C (Sc-7292), Bax (Sc-526), Bak (Sc-7873), VEGF-A (Sc-7269), VEGFR2 (Sc-504), Caspase-9 (Sc-7885), and Caspase-3 (Sc-7148) were purchased from Santa Cruz Biotechnology (Santa Cruz, CA, USA). BAD antibody (B31420) was purchased from Transduction Laboratories (Lexington,
KY, USA). Antibody to Smac (AF7891) was purchased from R\&D Systems (Minneapolis, MN, USA).

\section{Reagents}

Caspase-3 inhibitor z-DEVD-fmk (FMK004; used at $20 \mu \mathrm{M}$ throughout) and recombinant cytokines TNF- $a$ (210-TA) (used at $17 \mathrm{ng} / \mathrm{ml}$ throughout), FasL (126FL/CF; used at $17 \mathrm{ng} / \mathrm{ml}$ throughout), TRAIL (375-TL; used at $17 \mathrm{ng} / \mathrm{ml}$ throughout), and VEGF-A (293-VE-10; used at $19 \mathrm{ng} / \mathrm{ml}$ throughout) were purchased from R\&D Systems. 2-Deoxyglucose (D8375), NaF (201154), and NEM (E3876) were purchased from Sigma (St Louis, MO, USA). Live/Dead Assay Kit (L3224) was purchased from Invitrogen (Carlsbad, CA, USA). CHX (239763) was purchased from Calbiochem (San Diego, CA, USA). AZ58 is a proprietary Smac mimetic ${ }^{29,30}$ provided by Astra Zeneca (Boston, MA, USA).

Western blotting and densitometry

Cells were lysed using whole-cell lysis buffer $(50 \mathrm{mM}$ Tris-HCL, $\mathrm{pH}$ 7.4; $150 \mathrm{mM} \mathrm{NaCl} ; 5$ mM EDTA; 25 mM NaF; 1\% Triton-X 100; 1\% NP-40; 0.1 mM $\mathrm{Na}_{3} \mathrm{VO}_{4} ; 12.5 \mathrm{mM} \beta$-glycerophosphate; $1 \mathrm{mM}$ PMSF, and complete protease inhibitor cocktail (Roche)) by incubation on ice for 30-40 min with intermittent vortexing every $10 \mathrm{~min}$. The lysates were clarified at $13000 \mathrm{r}$. p.m. for $10 \mathrm{~min}$, and the supernatants were quantified and subjected 
to SDS-PAGE and western blotting on nitrocellulose membranes. The $5 x$ SDS-PAGE sample buffer used was as follows: $375 \mathrm{mM}$ Tris, pH 6.8; $0.01 \%$ bromophenol blue; $10 \%$ glycerol; $2 \%$ SDS; and $12.5 \% \beta$-mercaptoethanol. Blot images were quantified using the ImageJ software v1.45 s $(\mathrm{NIH}$, Bethesda, MD, USA) where appropriate.

\section{Blebbishield-mediated transformation assay}

Cell were plated at a density of 200000 cells $/ \mathrm{ml}(10 \mathrm{ml}$ per $100-\mathrm{mm}$ plate or $15 \mathrm{ml}$ per T-75 flask) and treated $24 \mathrm{~h}$ later as indicated in the figures. Twenty-four hours after treatment (or at the times indicated in figures), the floating pyknotic cells were collected, pelleted at 1200 r.p.m. for $3 \mathrm{~min}$ at room temperature, and re-plated in triplicate with complete MEM for a further $16-24 \mathrm{~h}$. The floating cells were then washed off, and the attached spheres were counted.

Isolation of mitochondria and mitochondria-depleted cytoplasm Mitochondria and cytosolic fractions were isolated by differential centrifugation as described previously. ${ }^{31}$ For depleting mitochondria from cytosol, the cytosolic fraction was clarified at 13000 r.p.m. for $10 \mathrm{~min}$. Mitochondria were lysed with whole-cell lysis buffer (as described in the Western blotting section).

\section{Preparation of nuclear and cytoplasmic extracts}

RT4v6 cells were plated in $10-\mathrm{cm}$ plates at a density of $50000 \mathrm{cell} / \mathrm{s} / \mathrm{ml}$ and treated with or without TNF- $a$ plus AZ58 for $8 \mathrm{~h}$. The cells were then subjected to nuclear and cytoplasmic extract fractionation using the NE-PER Nuclear and Cytoplasmic Extraction Kit (Pierce: 78833; Rockford, IL, USA) per the manufacturer's instructions.

\section{Quantification of DNA fragmentation}

RT4v6 cells ( $50000 / \mathrm{ml}, 4 \mathrm{ml} /$ well) were plated in six-well plates and treated $24 \mathrm{~h}$ later with various cytokines and chemicals as indicated in the figures for the indicated durations. Both floating cells and trypsinized adherent cells were subjected to PI-FACS as described previously. ${ }^{6}$

\section{Quantification of secondary necrosis}

RT4v6 cells were treated with or without various cell death-inducing treatments as indicated in the figures for $24 \mathrm{~h}$, and the floating pyknotic cell populations were isolated (trypsin was avoided throughout the protocol except for excluding auto-fluorescence and live control cells). Cells were pelleted down at 3500 r.p.m. for $5 \mathrm{~min}$, and cells were resuspended and incubated for $20 \mathrm{~min}$ in $100 \mathrm{nM}$ calcein-AM and $8 \mu \mathrm{M}$ ethidium homodimer-1 containing PBS at room temperature (Live/Dead Cytotoxicity Kit, Invitrogen) before analysis by flow cytometry. The FACS files were merged using the Flowjo software (Ashland, OR, USA).

Secondary necrotic PARP cleavages after apoptotic PARP cleavage (50 and $42 \mathrm{kDa}$ after $89 \mathrm{kDa}$ ) were quantified using western blotting and densitometry as described in the Western blotting section.

\section{Glycolysis and oligomerization analysis}

For glucose metabolism studies, 200000 cells were plated and treated as indicated in the figures, and blebbishields were isolated as described above. The conditioned media at the indicated time points were collected separately for metabolite analysis as described below. Blebbishields were counted and plated further in complete MEM at a density of $100000 \mathrm{blebbishields/ml;} \mathrm{conditioned} \mathrm{media} \mathrm{were} \mathrm{collected} \mathrm{and}$ clarified at 3500 r.p.m.; and the supernatants were frozen until analysis. The conditioned media were examined for the levels of glucose and lactic acid using YSI 2900 Biochemistry Analyzer (YSI Life Sciences, Yellow Springs, $\mathrm{OH}, \mathrm{USA}$ ) per the manufacturer's instructions. Increase in lactate production was calculated by subtracting the lactate present in the control medium (without exposure to cells; the lactate is from FBS) from the lactate present in the experimental media. Glucose uptake was calculated by subtracting the glucose levels of the experimental media from the glucose level of the control medium.

For oligomerization studies, the cells were induced for apoptosis using FasL plus AZ58 with or without $5 \mathrm{mM}$ 2-DG (in MEM that had equal molar normal glucose) or $20 \mathrm{mM} \mathrm{NaF}$ and $1 \mathrm{mM}$ NEM before immunoblotting. For experiments comparing RT4v6 with $253 \mathrm{~J}-\mathrm{P}$ cells for lactate production, 200000 cells $/ \mathrm{ml}$ were plated, and $24 \mathrm{~h}$ later, conditioned media were subjected to glucose and lactate measurement, and the cells were counted to examine the differences in proliferation.

\section{K-Ras activation assays}

Active ras pull-down assay was performed as previously described with minor modifications. GST expression plasmid Raf1-RBD (Ras binding domain)-aa1-149 (Dr. Channing Der; Addgene-13338; described in Brtva et al. $^{32}$ ) and control GST (a gift from Dr. Santosh Chauhan, The University of New Mexico, USA) were induced in DH5a with $1 \mathrm{mM}$ IPTG for $4 \mathrm{~h}$ at $37^{\circ} \mathrm{C}$ and the GST fusion proteins were purified as described previously. ${ }^{33}$ Two hundred micrograms of cell lysate in $200 \mu \mathrm{l}$ of whole-cell lysis buffer per condition was diluted with $200 \mu \mathrm{l}$ of magnesium-containing lysis buffer (MLB: $25 \mathrm{mM}$ HEPES, pH 7.5; $150 \mathrm{mM} \mathrm{NaCl} ; 1 \%(\mathrm{w} / \mathrm{v}) \mathrm{NP}-40 ; 0.25 \%(\mathrm{w} / \mathrm{v})$ sodium deoxycholate; $10 \%$ glycerol; $20 \mathrm{mM} \mathrm{MgCl}$; 1 mM EDTA; freshly added protease inhibitor cocktail (Roche); and $1 \mathrm{mM} \mathrm{PMSF}$ ) and subjected to pull-down using freshly purified GST/GST-RBD for $1 \mathrm{~h}$ at $4^{\circ} \mathrm{C}$. The bound proteins were washed six times using MLB and subjected to SDS-PAGE and western blotting for the target proteins as indicated in the figures.

\section{Double immunofluorescence}

Cells were fixed at room temperature for $15 \mathrm{~min}$ (4\% paraformaldehyde in PBS), washed, blocked (blocking buffer: 1\% BSA and 0.3\% Triton-X100 in PBS) for $1 \mathrm{~h}$, incubated with primary antibodies for $16 \mathrm{~h}$ at $4{ }^{\circ} \mathrm{C}$ (K-Ras $1: 50$ and Syntaxin- 6 antibodies $1: 100$ in blocking buffer), washed, incubated with secondary antibodies for $1 \mathrm{~h}$ at room temperature (Alexa-555 anti-mouse and Alexa-488 anti-rabbit; Invitrogen), washed, and incubated with $10 \mathrm{nM}$ Hoechst-33342 (Sigma) for 20 min before imaging.

Two-dimensional imaging and time-lapse microscopy

All imaging studies were performed with an Olympus IX81 microscope equipped with heating stage $\left(37^{\circ} \mathrm{C}\right)$ and humidified $\mathrm{CO}_{2}$ chamber $(5 \%)$. Image processing was carried out as described previously. ${ }^{2}$

\section{Statistical analyses}

Statistical analyses were performed using Microsoft Excel 2010. The statistical significance was determined based on Student's $t$ test with twotailed distribution and two-sample unequal variance, and $P$-values $<0.05$ were considered significant. The error bars represent S.Es., except the error bars for glucose and lactate measurements, which represent S.Ds.

\section{ABBREVIATIONS}

c-IAP2, cellular-inhibitor of apoptotic protein-2; IRES, internal ribosome entry site; MOMP, mitochondrial outer membrane permeabilization; p70S6K, 70 kDa ribosomal S6 kinase; XIAP, X-linked inhibitor of apoptosis; VEGF-A, vascular endothelial growth factor-A; TNF- $a$, tumor necrosis factor- $a$; TRAIL, tumor necrosis factor related apoptosis inducing ligand FasL, Fas ligand; PARP, poly ADP ribose polymerase; GST, glutathione Stransferase; LDH-A, lactate dehydrogenase-A.

\section{ACKNOWLEDGEMENTS}

We sincerely thank Dr. David J McConkey for providing various bladder cancer cell lines and various reagents used in this study and discussing data; Dr. Channing Der for GST-RBD of Raf-1 plasmid (Addgene-13338); Ms. I-Ling Lee for technical help, and Ms. Stephanie Deming for editorial assistance.

\section{AUTHOR CONTRIBUTIONS}

GGJ conceived the hypothesis, designed the study, performed all experiments, interpreted the data, and wrote the manuscript. GGJ, JRM, and GBM contributed to the measurements of glucose and lactate. NML contributed AZ58. AMK generated the RT4v6 cell line, interpreted the data, and provided scientific and editorial oversight. $\mathrm{LH}$ and MBE contributed to lentiviral production (data not shown). All authors revised this manuscript and agreed to its contents.

\section{COMPETING INTERESTS}

NML is an employee and shareholder of Astra Zeneca. Astra Zeneca provided us the Smac mimetic AZ58. All the other authors declare no conflict of interest. 


\section{REFERENCES}

1 Silva MT. Secondary necrosis: the natural outcome of the complete apoptotic program. FEBS Lett 2010; 584: 4491-4499.

2 Jinesh GG, Choi W, Shah JB, Lee EK, Willis DL, Kamat AM. Blebbishields, the emergency program for cancer stem cells: sphere formation and tumorigenesis after apoptosis. Cell Death Differ 2013; 20: 382-395.

3 Tsujimoto Y. Apoptosis and necrosis: intracellular ATP level as a determinant for cell death modes. Cell Death Differ 1997; 4: 429-434.

4 Silvera D, Formenti SC, Schneider RJ. Translational control in cancer. Nat Rev Cancer 2010; 10: 254-266.

5 Marash L, Kimchi A. DAP5 and IRES-mediated translation during programmed cell death. Cell Death Differ 2005; 12: 554-562.

6 Jinesh GG, Chunduru S, Kamat AM. Smac mimetic enables the anticancer action of BCG-stimulated neutrophils through TNF-alpha but not through TRAIL and FasL. J Leukoc Biol 2012; 92: 233-244.

7 Jinesh GG, Kamat AM. Redirecting neutrophils against bladder cancer cells by BCG and Smac mimetic combination. Oncoimmunology 2012; 1: 1161-1162.

8 Kawasome H, Papst P, Webb S, Keller GM, Johnson GL, Gelfand EW et al. Targeted disruption of p70(s6k) defines its role in protein synthesis and rapamycin sensitivity. Proc Natl Acad Sci USA 1998; 95: 5033-5038.

9 Gobeil S, Boucher CC, Nadeau D, Poirier GG. Characterization of the necrotic cleavage of poly(ADP-ribose) polymerase (PARP-1): implication of lysosomal proteases. Cell Death Differ 2001; 8: 588-594.

10 Sears R, Nuckolls F, Haura E, Taya Y, Tamai K, Nevins JR. Multiple Ras-dependent phosphorylation pathways regulate Myc protein stability. Genes Dev 2000; 14 : 2501-2514.

11 Babij C, Zhang Y, Kurzeja RJ, Munzli A, Shehabeldin A, Fernando M et al. STK33 kinase activity is nonessential in KRAS-dependent cancer cells. Cancer Res 2011; 71: $5818-5826$

12 Adhikary S, Eilers M. Transcriptional regulation and transformation by Myc proteins. Nat Rev Mol Cell Biol 2005; 6: 635-645.

13 Moon BS, Jeong WJ, Park J, Kim TI, Min do S, Choi KY. Role of oncogenic K-Ras in cancer stem cell activation by aberrant Wnt/beta-catenin signaling. $J$ Natl Cancer Inst 2014; 106: djt373.

14 Pylayeva-Gupta Y, Grabocka E, Bar-Sagi D. RAS oncogenes: weaving a tumorigenic web. Nat Rev Cancer 2011; 11: 761-774.

15 Hardwick JM, Soane L. Multiple functions of BCL-2 family proteins. Cold Spring Harb Perspect Biol 2013; 5: a008722.

16 Eskes R, Desagher S, Antonsson B, Martinou JC. Bid induces the oligomerization and insertion of Bax into the outer mitochondrial membrane. Mol Cell Biol 2000; 20: 929-935.

17 Wei MC, Zong WX, Cheng EH, Lindsten T, Panoutsakopoulou V, Ross AJ et al. Proapoptotic BAX and BAK: a requisite gateway to mitochondrial dysfunction and death. Science 2001; 292: 727-730.

18 Gao G, Dou QP. N-terminal cleavage of bax by calpain generates a potent proapoptotic 18-kDa fragment that promotes bcl-2-independent cytochrome $\mathrm{C}$ release and apoptotic cell death. J Cell Biochem 2000; 80: 53-72.

19 Wang CY, Mayo MW, Baldwin AS Jr. TNF- and cancer therapy-induced apoptosis: potentiation by inhibition of NF-kappaB. Science 1996; 274: 784-787.
20 Fang X, Yu S, Eder A, Mao M, Bast Jr RC, Boyd D et al. Regulation of BAD phosphorylation at serine 112 by the Ras-mitogen-activated protein kinase pathway. Oncogene 1999; 18: 6635-6640.

21 Jinesh GG, Laing NM, Kamat AM. Smac mimetic with TNF-alpha targets Pim-1 isoforms and reactive oxygen species production to abrogate transformation from blebbishields. Biochem J 2016; 473: 99-107.

22 Jinesh GG, Kamat AM. Endocytosis and serpentine filopodia drive blebbishieldmediated resurrection of apoptotic cancer stem cells. Cell Death Discov 2015; 1: 15069.

23 Danial NN, Gramm CF, Scorrano L, Zhang CY, Krauss S, Ranger AM et al. BAD and glucokinase reside in a mitochondrial complex that integrates glycolysis and apoptosis. Nature 2003; 424: 952-956.

$24 \mathrm{Hu}$ Y, Lu W, Chen G, Wang P, Chen Z, Zhou Y et al. K-ras(G12V) transformation leads to mitochondrial dysfunction and a metabolic switch from oxidative phosphorylation to glycolysis. Cell Res 2012; 22: 399-412.

25 Short JD, Houston KD, Dere R, Cai SL, Kim J, Johnson CL et al. AMP-activated protein kinase signaling results in cytoplasmic sequestration of p27. Cancer Res 2008; 68: 6496-6506.

26 Luders J, Pyrowolakis G, Jentsch S. The ubiquitin-like protein HUB1 forms SDSresistant complexes with cellular proteins in the absence of ATP. EMBO Rep 2003; 4: $1169-1174$.

27 Gatenby RA, Gillies RJ. Why do cancers have high aerobic glycolysis? Nat Rev Cancer 2004; 4: 891-899.

28 Goodwin Jinesh G, Willis DL, Kamat AM. Bladder cancer stem cells: biological and therapeutic perspectives. Curr Stem Cell Res Ther 2014; 9: 89-101.

29 Hennessy EJ, Adam A, Aquila BM, Castriotta LM, Cook D, Hattersley M et al. Discovery of a novel class of dimeric Smac mimetics as potent IAP antagonists resulting in a clinical candidate for the treatment of cancer (AZD5582). J Med Chem 2013; 56: 9897-9919.

30 Lee EK, Jinesh GG, Laing NM, Choi W, McConkey DJ, Kamat AM. A Smac mimetic augments the response of urothelial cancer cells to gemcitabine and cisplatin. Cancer Biol Ther 2013; 14: 812-822.

31 Graham JM. Isolation of mitochondria from tissues and cells by differential centrifugation. Curr Protoc Cell Biol 2001; Chapter 3: Unit 3.3

32 Brtva TR, Drugan JK, Ghosh S, Terrell RS, Campbell-Burk S, Bell RM et al. Two distinct Raf domains mediate interaction with Ras. J Biol Chem 1995; 270: 9809-9812.

33 Taylor SJ, Resnick RJ, Shalloway D. Nonradioactive determination of Ras-GTP levels using activated ras interaction assay. Methods Enzymol 2001; 333: 333-342.

34 Chiu R, Novikov L, Mukherjee S, Shields D. A caspase cleavage fragment of p115 induces fragmentation of the Golgi apparatus and apoptosis. J Cell Biol 2002; 159: $637-648$

c) (i)

This work is licensed under a Creative Commons Attribution 4.0 International License. The images or other third party material in this article are included in the article's Creative Commons license, unless indicated otherwise in the credit line; if the material is not included under the Creative Commons license, users will need to obtain permission from the license holder to reproduce the material. To view a copy of this license, visit http://creativecommons.org/licenses/ by/4.0/

Supplementary Information accompanies the paper on the Cell Death and Discovery website (http://www.nature.com/cddiscovery) 